\title{
Implicações clínicas das relações celulares na infecção pelo SARS-CoV-2 e desfechos da COVID-19: Revisão Integrativa da Literatura
}

Clinical Implications of Cellular Ratios in SARS-CoV-2 Infection and Outcomes of COVID-19: An

\author{
Integrative Literature Review
}

Implicaciones clínicas de las relaciones celulares en la infección por SARS-CoV-2 y resultados de COVID-19: Una Revisión Bibliográfica Integradora

Recebido: 18/11/2021 | Revisado: 25/11/2021 | Aceito: 28/11/2021 | Publicado: 10/12/2021

Mônica Ferreira Silva Cruvinel ORCID: https://orcid.org/0000-0003-2941-7005

Universidade de Uberaba, Brasil

E-mail: mfscru@hotmail.com

Davi de Lima Silva

ORCID: https://orcid.org/0000-0002-8118-6817

Universidade de Uberaba, Brasil

E-mail: lima.210davi@gmail.com

Thaís Ferreira da Silva

ORCID: https://orcid.org/0000-0001-6982-0435

Universidade de Uberaba, Brasil

E-mail: tha_ferreira1999@ @otmail.com

Maria Vitória Pereira Hillades

ORCID: https://orcid.org/0000-0001-8788-1880 Universidade de Uberaba, Brasil

E-mail: mariavitoriahillades@gmail.com

Tiago Soares Bernardes

ORCID: https://orcid.org/0000-0003-2418-3609

Universidade de Uberaba, Brasil

E-mail: tiago.soaresbernardes7@gmail.com

Michel Reis Abdalla

ORCID: https://orcid.org/0000-0002-6663-8395

Centro Universitário INTA, Brasil

E-mail: drmichelabdalla@gmail.com

Douglas Reis Abdalla

ORCID: https://orcid.org/0000-0002-6971-1201 Universidade de Uberaba, Brasil

Faculdade de Talentos Humanos, Brasil

E-mail: drabdalla@facthus.edu.br

\begin{abstract}
Resumo
Uma ferramenta promissora para atuar como biomarcadores circulantes são as relações celulares, que refletem a inflamação sistêmica, sendo potenciais preditores para o prognóstico de mortalidade em várias populações. Portanto, o objetivo desta revisão consiste em discutir a conformidade entre as relações celulares e seus significados na infecção COVID-19. No presente estudo foi conduzida uma revisão integrativa. Após a definição da questão norteadora, localização e seleção dos artigos, foram identificadas 491 publicações potencialmente elegíveis. Após a aplicação dos critérios de inclusão e exclusão a amostra foi composta por 35 artigos. Constatou-se que a elevação das relaçães celulares do sangue periférico indicam desfecho clínico insatisfatório de COVID-19. Os pacientes com essas relações celulares elevadas apresentaram maior incidência de síndrome do desconforto respiratório agudo, maior taxa de necessidade de ventilação mecânica e maiores taxas de mortalidade. Em conclusão, constatou-se que houve associação entre o valor quantitativo das relações celulares com a evolução do paciente com COVID-19. Observou-se que quanto maior forem as relações neutrófilo/linfócito, plaqueta/linfócito e linfócito/monócito, pior será o prognóstico do paciente infectado pelo SARS-CoV 2. Mais pesquisas são necessárias para confirmar esses achados e para comparar a capacidade preditiva das relações na evolução da infecção da COVID-19.
\end{abstract}

Palavras-chave: COVID-19; SARS-CoV-2; Inflamação; Prognóstico.

\begin{abstract}
A promising tool to act as circulating biomarkers are cellular ratios, which reflect systemic inflammation and are potential predictors for mortality prognosis in various populations. Therefore, the aim of this review is to discuss the compliance of cellular relationships and their significance in COVID-19 infection. In the present study, an integrative
\end{abstract}


review was conducted. After defining the guiding question, locating and selecting articles, 491 potentially eligible publications were identified. After applying the inclusion and exclusion criteria, the sample consisted of 35 articles. It was found that elevated peripheral blood cell ratios indicate unsatisfactory clinical outcome of COVID-19. Patients with these elevated cell ratios had higher incidence of acute respiratory distress syndrome, higher rate of need for mechanical ventilation, and higher mortality rates. In conclusion, it was found that there was an association between the quantitative value of the cell ratios with the evolution of the patient with COVID-19. It was observed that the higher the neutrophil/lymphocyte, platelet/lymphocyte, and lymphocyte/monocyte ratios, the worse the prognosis of the patient infected with SARS-CoV 2. Further research is needed to confirm these findings and to compare the predictive ability of the ratios in the evolution of COVID-19 infection.

Keywords: COVID-19; SARS-CoV-2; Inflammation; Prognosis.

\section{Resumen}

Una herramienta prometedora para actuar como biomarcadores circulantes son los ratios celulares, que reflejan la inflamación sistémica, siendo potenciales predictores del pronóstico de mortalidad en diversas poblaciones. Por lo tanto, el objetivo de esta revisión es discutir el cumplimiento de las relaciones celulares y su importancia en la infección por COVID-19. En el presente estudio se realizó una revisión integradora. Tras definir la pregunta guía, localizar y seleccionar los artículos, se identificaron 491 publicaciones potencialmente elegibles. Tras aplicar los criterios de inclusión y exclusión, la muestra quedó compuesta por 35 artículos. Se descubrió que los índices elevados de células sanguíneas periféricas indican un resultado clínico insatisfactorio de COVID-19. Los pacientes con estos índices celulares elevados tenían una mayor incidencia de síndrome de dificultad respiratoria aguda, mayor necesidad de ventilación mecánica y mayores tasas de mortalidad. En conclusión, se encontró que había una asociación entre el valor cuantitativo de los ratios celulares con la evolución del paciente con COVID-19. Se observó que cuanto más altos eran los ratios neutrófilos/linfocitos, plaquetas/linfocitos y linfocitos/monocitos, peor era el pronóstico del paciente infectado por el SARS-CoV 2. Se necesitan más investigaciones para confirmar estos hallazgos y comparar la capacidad predictiva de los ratios en la evolución de la infección por COVID-19.

Palabras clave: COVID-19; SARS-CoV-2; Inflamación; Pronóstico.

\section{Introdução}

Em dezembro de 2019 na China, houve o aparecimento de uma infecção pulmonar causada por um novo tipo de coronavírus, denominado SARS-CoV-2. Essa mesma infecção pulmonar foi considerada uma pandemia três meses depois e a doença em questão recebeu o nome de COVID-19. Desde então, o mundo enfrenta grandes desafios para conter seu avanço, elucidar seu tratamento e evitar o agravamento dos quadros da doença (OMS, 2020).

No Brasil, a doença se iniciou em fevereiro de 2020, prosseguindo com aumento notadamente grande de pessoas infectadas, sendo que a maior parte dos casos está concentrada na região Sudeste. Dentre o total de óbitos, a maioria apresentava pelo menos um fator de risco. A cardiopatia foi a principal comorbidade e a maioria dos indivíduos tinha 60 anos ou mais, com predominância do sexo masculino (OMS, 2020).

O agente causador da COVID-19 é o SARS-CoV-2, um novo coronavírus que faz parte da família coronaviridae. Nos seres humanos, os coronavírus causam infecções respiratórias de gravidade diversa, sendo um dos mais frequentes agentes do resfriado comum, também reconhecidas causas de pneumonias graves como a síndrome respiratória aguda grave e a síndrome respiratória do Oriente Médio, descrita em 2012, respectivamente causadas por SARS-CoV e MERS-CoV. A síndrome respiratória aguda grave por coronavírus (SARS-CoV-2) é causada por um betacoronavírus antes desconhecido, que foi descoberto em amostras de lavagem broncoalveolar obtida nos núcleos de pacientes com pneumonia de causa desconhecida na cidade de Wuhan, na China. A maioria dos pacientes no estágio inicial desse surto relatou uma relação com o Mercado de peixe de Huanan no Sul da China, um mercado de animais vivos ou "úmido", o que sugere que o vírus tenha origem zoonótica. Outros estudos sugerem que o SARS-CoV-2 pode ser um vírus recombinante entre um coronavírus de morcego e um coronavírus de origem desconhecida (Guan et al., 2020; Li et al., 2020; OMS, 2020).

As principais formas de transmissão do SARS-CoV-2 de acordo com a Organização Mundial da Saúde (2020), são: contato direto, gotículas, aerossóis e fômites contaminados. A transmissão através do contato direto, indireto ou em proximidade ocorre quando indivíduos infectados tossem, espirram ou falam, permitindo que gotículas com diâmetro > 5-10 
$\mu \mathrm{m}$, da saliva ou secreções do trato respiratório superior sejam transferidas para a pessoa saudável, através da orofaringe, narinas e olhos. Os aerossóis são definidos como gotículas $<5-10 \mu \mathrm{m}$ de ar infectado com partículas virais, e suspensas no ar por esticadas distâncias e tempo, permitindo a infecção através da inspiração do ar. E, por fim, as gotículas ou aerossóis com partículas virais podem contaminar superfícies e objetos, desenvolvendo as fômites - superfícies contaminadas, que em contato direto ou indireto, indivíduos podem se contaminar (Guan et al., 2020; Li et al., 2020; OMS, 2020).

A infecção por SARS-CoV-2 apresenta período de incubação estimado de aproximadamente 5 a 6 dias, podendo variar de 2 a 14 dias (Guan et al., 2020; Li et al., 2020). Os casos confirmados da COVID-19 podem ser sintomáticos ou assintomáticos (OMS, 2020). Segundo Chan (2020) e Wu \& MCgoogan (2020), os quadros sintomáticos podem ser leves (ausência de pneumonia ou presença leve), graves (dispnéia, hipóxia e comprometimento de mais de $50 \%$ do pulmão comprometido em exames de imagem ou críticos (choque séptico e falência de órgãos). Aproximadamente $86 \%$ dos casos sintomáticos, apresentam-se com formas leves e apenas $14 \%$ mostram-se com sinais e sintomas graves, necessitando de oxigenoterapia hospitalar, e 5\% desse grupo carecem de unidade de terapia intensiva (OMS, 2020). De acordo com Wu; MCGoogan (2020), qualquer indivíduo pode apresentar o desenvolvimento de quadros graves de SARS-CoV-2, entretanto, adultos com maior idade ou comorbidades associadas apresentam maior probabilidade de desenvolverem infecção por SARSCoV-2 grave. Lu et al. (2020) efetivaram um estudo que analisa as apresentações clínicas da infecção por SARS-Cov 2 e, os sintomas principais, foram: febre (88,3\%); tosse (68,6\%); mialgia ou fadiga (35,8\%); expectoração $(23,2 \%)$; dispneia $(21,9 \%)$; cefaleia ou tontura $(12,1 \%)$; diarreia $(4,8 \%)$ e vômitos ou náuseas $(3,9 \%)$. Zhou et al. (2020), mostrou as evidências científicas da capacidade do SARS-CoV-2 levar à sepse e choque séptico.

O padrão ouro de diagnóstico para o COVID-19 é a realização do teste molecular da Reação em Cadeia da Polimerase (PCR), utilizando amostras da mucosa respiratória, como Swab nasofaríngeo ou aspirado brônquico (Böger et al., 2020). Embora esse teste tenha uma boa sensibilidade e especificidade, é possível ainda que ocorra casos de falsos negativos se a quantidade de genoma viral na amostra não for suficiente ou se o intervalo de tempo para a replicação viral não for alcançado. Segundo Lauer et al. (2020), o período médio de incubação, desde a infecção até o início dos sintomas, é estimado em 5 dias, mas é preciso destacar que resultados falso negativos em exames podem ser comuns nos primeiros 7 dias de infecção. (Böger et al., 2020)

A identificação de fatores de risco que podem predizer o curso da doença e a sua gravidade é muito importante para a classificação adequada dos riscos e o tratamento específico. Segundo Gallo et al. (2021), os principais fatores preditores de progressão da COVID-19 são: idade, comorbidades, resposta imune, achados radiográficos e marcadores laboratoriais. Já Fang et al. (2020) destaca fatores como sexo masculino, idade avançada e presença de comorbidades, como elementos com forte evidência de associação a uma maior severidade da doença.

De acordo com Ponti et al. (2020), a desregulação do sistema imune e o estado de hiperinflamação viral desempenham um papel fundamental no desenvolvimento das formas graves de COVID-19 e é provavelmente um fator importante em seu prognóstico. Dessa maneira, todos os pacientes com COVID- 19 devem ser rastreados para hiperinflamação por meio de exames laboratoriais simples, como hemograma e análise bioquímica sérica, que além de serem técnicas mais rápidas, rotineiras e fáceis de medir, também possuem baixo custo. Segundo Fu et al. (2020), durante a infecção, há a presença de vários parâmetros hematológicos anormais, tais como linfopenia, neutrofilia, níveis elevados de dímero D e fibrinogênio, entretanto a implicação clínica desses índices permanecem indefinidos. Há evidência acumulada de que a proporção de neutrófilos para linfócitos (NLR), a proporção de plaquetas para linfócitos (PLR) e a proporção de linfócitos para monócitos (LMR) são biomarcadores circulantes que refletem a inflamação sistêmica, sendo potenciais preditores para o prognóstico de mortalidade em várias populações de pacientes de COVID-19. Portanto, o objetivo desta revisão consiste em discutir a conformidade entre as relações celulares e seus significados na infecção COVID-19. 


\section{Metodologia}

No presente estudo foi conduzida uma revisão integrativa, que consiste em uma pesquisa que permite a partir de evidências a avaliação, síntese e conhecimento acerca de um fenômeno, objetivando produzir uma visão geral de conceitos complexos, teorias ou problemas de saúde relevantes a partir de estudos pré-existentes, possibilitando a proposição de intervenção (Galvão et al., 2004; Whittemore \& Knafl, 2005).

Para a seleção dos artigos, foram conduzidas 6 etapas metodológicas, quais sejam: 1. elaboração da questão norteadora ou hipótese da pesquisa, ou seja, identificou-se o problema, apresentou-se o mecanismo de busca e os descritores ou palavras chave; 2. estabelecimento dos critérios de inclusão e exclusão dos artigos a serem selecionados para composição da amostra; 3. leitura exploratória dos títulos e resumos dos artigos para pré-seleção; 4. leitura analítica dos artigos a fim de compilar, analisar e categorizar as informações; 5. interpretação dos resultados. 6. síntese seguida da apresentação dos resultados identificados, que permeiam a questão norteadora (De Sousa et al., 2011).

Portanto, neste estudo optou-se por realizar busca sobre os conceitos: covid 19, prognóstico, proporção de neutrófilos para linfócitos (NLR), proporção de plaquetas para linfócitos (PLR), proporção de linfócitos para monócitos (LMR) e SARSCoV-2. A partir desses conceitos, definiu-se a questão norteadora: qual a significância de saber as relações e proporções celulares em um paciente com COVID-19?

Após a formulação da questão a ser pesquisada, foi realizado um levantamento bibliográfico na plataforma PubMed. O levantamento do estudo ocorreu entre maio a julho de 2021. E a seleção dos textos procedeu com as buscas na plataforma, utilizando os filtros nela disponível para textos publicados entre 2010 e 2021. Para seleção das publicações, foram adotados os seguintes critérios de inclusão: artigos científicos, publicados no idioma Inglês, entre os anos de 2010 a 2020, disponíveis online e gratuitamente na íntegra. Foram excluídos os artigos sem resumo na base de dados ou incompletos, editoriais, cartas ao editor, estudos reflexivos, revisões sistemáticas ou integrativas de literatura.

Após a definição da questão norteadora, localização e seleção dos artigos, foram identificadas 491 publicações potencialmente elegíveis para serem incluídas nessa revisão. Após a aplicação dos critérios de inclusão e exclusão a amostra foi composta por 80 publicações, foram analisados os resumos de 36 registros, para verificar se atenderiam os critérios de elegibilidade e se responderiam à pergunta que norteia esta revisão, assim excluiu-se 01 registros e somente 35 foram analisados na íntegra para confirmar a elegibilidade para a síntese quantitativa e análise dos dados.

\section{Resultados e Discussão}

No espaço de tempo delimitado para a realização deste estudo (2020-2021) foram encontradas e analisadas 35 publicações. Em 2020 foram publicados 31 artigos (88,5\%) e, em 2021, foram publicados 4 artigos (11,4\%) conforme Tabela 1.

De acordo com a metodologia dos trabalhos selecionados os tipos de estudo eram pesquisa pré-clínicas utilizando e linhagens celulares de tumores HPV dependentes.As publicações resultaram de diferentes revistas sendo: Journal of Infection, Thrombosis Research, Journal of Soc, Respiratory Research, Medicine Buenos Aires, Crit Care, Int Immunopharmacology, International Journal of - Clinical Medicine, International Journal of Antimicrobial Agents, Journal of Translational Medicine, European Journal of Clinical Investigation, Epidemiology and Infection, Aging, American Journal of Emergency Medicine, Gaceta Médica de México, Iranian Journal of Microbiology, Journal of Global Antimicrobial Resistance - Journal, Caspian. 
Quadro 1. Artigos levantados para compor a revisão acerca das relações celulares e a COVID-19.

\begin{tabular}{|c|c|c|c|}
\hline Referência & $\begin{array}{c}\text { Ano de } \\
\text { publicação }\end{array}$ & Tipo de Estudo & Objetivos do estudo \\
\hline
\end{tabular}

$\begin{array}{lll}\text { Liu et al. } & 2020 & \text { Coorte Retrospectivo } \\ \text { Fu et al. } & 2020 & \text { Estudo Retrospectivo } \\ \text { Tatum et al } & 2020 & \begin{array}{c}\text { Revisão de registro } \\ \text { Retrospectivo }\end{array}\end{array}$

Investigar se o NLR pode servir como um valioso preditor de mortalidade intra-hospitalar.

Analisar a correlação entre os parâmetros hematológicos e os diferentes grupos de gravidade do COVID-19.

Determinar o valor prognóstico da proporção de neutrófilos para linfócitos (NLR) em pacientes com COVID hospitalizados em áreas com a maior prevalência de casos e taxas altas de obesidade e outras comorbidades.

Coorte Retrospectivo

Ye et al.

Ma et al.

Yang et al

Chan et al.

Ciccullo et al

Wang et al.

Seyit et al

Liu et. al

Jimeno et al

Kong et al

Lian et al

Cai et al.

Téllez et al.
Estudo Retrospectivo

Estudo Retrospectivo

Estudo Retrospectivo

Meta-análise

Estudo Retrospectivo

Meta-análise

Estudo Retrospectivo

Coorte Prospectivo

Estudo Observacional Retrospectivo

Coorte Retrospectivo

Estudo Retrospectivo

Coorte Retrospectivo

Estudo Retrospectivo
Avaliar o valor prognóstico do a proporção de neutrófilos para linfócitos (NLR) na infecção por COVID-19. Para isso, avaliou-se um coorte retrospectivo de 131 pacientes com COVID-19 de março a maio de 2020.

Avaliar a utilidade prognóstica das alterações dinâmicas do D-Dímero e NLR, especialmente o teste inicial na admissão e valor de pico durante a internação, em pacientes com COVID-19

Analisar a habilidade do NLR em predizer SDRA (Síndrome do Desconforto Respiratório Agudo).

Determinar o efeito do sexo, idade, PCR, contagem de leucócitos, NLR, LMR, PLR e comorbidades no tempo de internação de pacientes com pneumonia COVID-19.

Identificar a associação de NLR e PLR em relação à gravidade de COVID19.

Avaliar os preditores de evolução clínica. Para isso, foi analisado retrospectivamente um grupo de 74 pacientes com COVID-19 confirmado hospitalizados em nosso centro em março de 2020.

Analisar a robustez da proporção de neutrófilos para linfócitos CD4+ (NCD4LR) na previsão do tempo de conversão negativa (NCT) de SARS CoV-2 em pacientes com COVID-19

Investigar e comparar os impactos prognósticos da PCR, contagem de leucócitos, NLR, PLR, biomarcadores de largura de distribuição de glóbulos vermelhos (RDW) em casos COVID-19 confirmados em laboratório, bem como para explorar os biomarcadores diagnósticos mais úteis e valores de corte ideais em pacientes COVID-19

Rastrear o fator preditivo mais útil para doenças críticas por COVID-19.

Teve- se como objetivo um levantamento da hipótese de que o NLR, como um marcador de disfunção endotelial, pode ser útil na identificação de pacientes com mau prognóstico em casos de COVID-19 hospitalizados

Teve-se como objetivo investigar a associação entre diferentes dados laboratoriais (incluindo subconjuntos de linfócitos e biomarcadores inflamatórios) e características clínicas de pacientes hospitalizados com infecção por COVID-19 leve e grave para revelar um fator prognóstico potencialmente útil associado à morbidade grave.

Objetivou-se investigar a correlação da NLR com doença crítica em pacientes idosos com COVID-19 e avaliar o poder prognóstico do NLR na admissão.

Teve como objetivo buscar a validação da NLR como um indicador que auxilie na tomada de decisão clínica quanto ao início do tratamento com corticosteróides em indivíduos com Covid-19

Avaliar a eficácia da relação linfócitos/ neutrófilos (LNR) e neutrófilos/monócitos (NMR) como predictores de mortalidade em pacientes com COVID-19 
Xisheng Yan et al.

$\mathrm{Xu}$ et al.

Zhang et al.

Nalbant et al.

Wang et al.

Liu et al.

Qun et al.

Liu et al.

Pimentel et al.

Eslamijouybari et al.

Mousavi-Nasab et al.

Moradi et al.

Seyit et al.

Yufei et al.

Javanmard et al.

Belice at al.

Sànchez et al.

2021

Seyit et al.
Coorte Retrospectivo

Estudo retrospectivo

Estudo Retrospectivo

Estudo Retrospectivo

Coorte Retroscpectivo

Coorte Retroscpectivo

Estudo Restrospectivo

Estudo Retrospectivo

Estudo Retrospectivo

Caso-Controle

Estudo retrospectivo

Coorte Retrospectivo

Estudo Retrospectivo

Estudo observacional retrospectivo

Estudo Retrospectivo

Estudo Retrospectivo

Estudo tranversal
Investigar se a NLR (Relação neutrófilo/ linfócito) é um fator prognóstico em pacientes com COVID - 19

Explorar se os fatores de inflamação basal, como a relação neutrófilo linfócito (NLR), proteína C reativa (PCR) e procalcitonina (PCT) estariam associados a um risco aumentado de morte em pacientes com COVID-19

Alcançar a fenotipagem imunológica de pacientes com COVID-19 com base na resposta IgG tardia e na relação NLR, buscando determinar a gravidade da doença e o resultado clínico

Investigar parâmetros do hemograma, como NLR, PLR, proteína C reativa e outros e suas associações com a COVID-19.

Explorar se a proporção de neutrófilos / linfócitos (NLR) e a proporção de plaquetas / linfócitos (PLR) estão associadas ao desenvolvimento de óbito em pacientes com COVID-19.

Explorar um nomograma fácil de usar e um modelo para fazer a triagem de pacientes em categorias de risco para determinar a probabilidade de desenvolver uma doença crítica.

Conduzir uma análise aprofundada para esclarecer alguns dos mecanismos patológicos da doença e identificar medidas simples para prever sua gravidade precocemente.

Identificar os preditores críticos que podem avaliar efetivamente as condições da doença de pacientes com COVID-19, analisando as características clínicas e achados laboratoriais de pacientes com infecção por SARS-CoV-2.

Destacar a importância da NLR em pacientes infectados pela pandemia de COVID-19. Para isso, reuniu os principais pontos de diversos estudos envolvendo o NLR.

Comparar os índices do hemograma (hemograma completo) entre pacientes com COVID-19 e o grupo controle, e avaliar a relação desses índices com o prognóstico do COVID-19.

Investigar a relação neutrófilos / linfócitos (NLR) com proteína C reativa para identificar potenciais preditores clínicos e analisar diferenças entre pacientes com COVID-19 grave e não grave

Avaliar o potencial preditivo do NRL em termos de mortalidade em COVID

Investigar e comparar os impactos prognósticos da PCR, contagem de leucócitos,NLR e PLR em casos COVID-19 confirmados em laboratório, bem como para explorar os biomarcadores diagnósticos mais úteis e valores de corte ideais em pacientes COVID-19.

Investigar o valor da detecção combinada da razão neutrófilos / linfócitos (NLR) e do nível de proteína $\mathrm{C}$ reativa (PCR) no diagnóstico de COVID19

Buscar um marcador prognóstico confiável de gravidade da doença COVID-19.

Comparar as razões neutrófilos-linfócitos de homens e mulheres com diagnóstico de COVID-19.

Estabelecer o melhor ponto de corte de NLR e LCR para predizer mortalidade em pacientes hospitalizados por COVID-19 no México

Investigar e comparar os impactos prognósticos de biomarcadores de CRP, contagem de leucócitos, NLR, PLR, largura de distribuição de células vermelhas (RDW) em casos COVID-19 confirmados em laboratório, bem como explorar os biomarcadores diagnósticos mais úteis e valores de corte ideais em pacientes COVID-19. 
Journal of Internal Medicine, Gastroenterology and Hepatology from Bed to Bench, Scandinavian Journal of Clinical and Laboratory Investigation, Journal of Global Antimicrobial Resistance - Journal, Journal of Global Antimicrobial Resistance Journal, Annals of Translational Medicine, Frontiers in Immunology, International Journal of Laboratory Hematology, Clinical Nutrition ESPEN, Epidemiology \& Infection, Microorganisms, Journal of Medical Virology, Scientific Reports, Frontiers in Molecular Biosciences, Revista da Associação Médica Brasileira, Cell Metabolism. Analisando os locais de estudo, 2 artigos foram realizados nos Estados Unidos (2,8\%), 18 artigos desenvolvidos no China (51,4\%), 1 realizados na Espanha $(2,8 \%), 1$ realizados na Itália $(2,8 \%), 4$ realizados na Turquia $(11,4 \%), 4$ realizados na Irã $(11,4 \%), 1$ realizados na Brasil (2,8\%), 3 realizados na México (8,5\%) e 1 realizados na Argentina (2,8\%).

No estudo de Liu et al. (2020), pretenderam investigar se o NLR pode servir como um valioso preditor de mortalidade intra-hospitalar. Para isso, um coorte de pacientes com COVID-19 internados no Hospital Zhongnan da Universidade de Wuhan de $1^{\circ}$ de janeiro a 29 de fevereiro foi analisada retrospectivamente. Os dados de linha de base de exames laboratoriais, incluindo NLR, foram coletados. Modelos de regressão logística univariada e multivariada foram desenvolvidos para avaliar a relação independente entre o NLR basal e todas as causas de morte hospitalar. Uma análise de sensibilidade foi realizada convertendo o NLR de uma variável contínua para uma variável categórica de acordo com o tercil. Análises de interação e estratificadas também foram conduzidas. Portanto, NLR é um fator de risco independente de mortalidade intra-hospitalar para pacientes com COVID-19, especialmente para homens. A avaliação da NLR pode ajudar a identificar indivíduos de alto risco com COVID-19.

Em pesquisa desenvolvida por Fu et al. (2020), realizaram um estudo retrospectivo de pacientes com COVID-19 no hospital designado em Suzhou, China para analisar a correlação entre os parâmetros hematológicos e os diferentes grupos de gravidade do COVID-19. Para isso, pacientes adultos confirmados com COVID-19 em Suzhou foram incluídos. Os dados dos pacientes foram coletados e os resultados dos exames laboratoriais foram comparados entre os grupos COVID-19 leve/ moderado e grave. Um ROC foi calculado para comparar o desempenho diagnóstico dos índices candidatos, e os níveis dinâmicos dos índices hematológicos foram comparados entre os dois grupos. Foram incluídos 75 pacientes, com idade média de 46,6 \pm 14 anos, e 45 pacientes eram do sexo masculino. Todos os pacientes foram classificados em dois grupos: o grupo leve / moderado e o grupo grave. WBC, razão de neutrófilos para linfócitos (NLR), dímero D e níveis de fibrinogênio do grupo grave foram significativamente maiores $(\mathrm{P}<0,05)$ do que o leve / moderado, e os linfócitos foram menores. O teste ROC mostrou que os parâmetros hematológicos tiveram uma AUC maior do que os fatores inflamatórios. Houve uma diferença significativa nos níveis de linfócitos e fibrinogênio entre os dois grupos no dia 1 ( $\mathrm{P}<0,05)$. No entanto, o NLR do grupo grave foi maior do que o leve / moderado nos dias 1, 4 e 14 (P <0,01), assim como o dímero D nos dias 1, 7 e 14 (P <0,05). Portanto, concluiu-se que índices hematológicos anormais COVID-19 comuns na admissão incluem hiperfibrinogenemia, linfopenia, a elevação do dímero D e leucopenia, que foram significativamente diferentes entre os grupos COVID-19 leve / moderado e grave. Além disso, a mudança dinâmica de NLR e nível de dímero D pode distinguir casos COVID-19 graves de leve / moderado.

Neste mesmo sentido, o estudo de Tatum et al. (2020), procuraram determinar o valor prognóstico da proporção de neutrófilos para linfócitos (NLR) em pacientes com COVID hospitalizados em 2 grandes áreas metropolitanas com a maior prevalência de casos e taxas excessivamente altas de obesidade e outras condições comórbidas. Para isso, realizou-se uma revisão de um registro prospectivo de pacientes adultos (mais de 18 anos) hospitalizados com SARS-CoV-2 de dois grandes hospitais de rede de segurança urbana em Louisiana. As contagens de células sanguíneas nos dias 2 e 5 foram usadas para obter NLR. A análise da curva Receiver Operating Characteristic (ROC) avaliou a capacidade preditiva de NLR na mortalidade. A análise de sobrevivência de Kaplan-Meier (KM) e os modelos de regressão de Cox examinaram o efeito da 
Research, Society and Development, v. 10, n. 16, e164101623482, 2021

(CC BY 4.0) | ISSN 2525-3409 | DOI: http://dx.doi.org/10.33448/rsd-v10i16.23482

NLR na sobrevivência. A população do estudo de 125 pacientes era maioritariamente afro-americana (88,6\%) e do sexo feminino (54,8\%), com média de idade e IMC de 58,7 e 34,2 anos. A maioria (96,0\%) apresentava comorbidades, sendo hipertensão (72,0\%), obesidade $(66,7 \%)$ e diabetes $(40,0 \%)$ as mais comuns. A mortalidade foi de $18,4 \%$. NLR> 4,94 no dia 1 de intubação prevista $(P=0,02)$. NLR acima dos valores de corte estabelecidos nos dias de hospital 2 e 5 , cada um previu mortalidade significativamente $(\mathrm{P}<0,001$ e $\mathrm{P}=0,002$, respectivamente). Portanto, a NLR é um fator prognóstico para intubação endotraqueal na admissão hospitalar e preditor independente para risco de mortalidade em pacientes com SARSCoV-2 em dias hospitalares subsequentes. Os esforços de pesquisa clínica devem examinar os efeitos de estratégias como a inibição da arginase por si só e / ou óxido nítrico inalado para melhorar os efeitos do NLR elevado.

Em trabalho publicado por Basbus et al (2020), objetivaram avaliar o valor prognóstico do a proporção de neutrófilos para linfócitos (NLR) na infecção por COVID-19. Para isso, avaliou-se um coorte retrospectivo de 131 pacientes com COVID19 de março a maio de 2020. Analisou-se a associação de um NLR = 3 com COVID-19 grave, características basais da população e a taxa de mortalidade. A idade média era de 52 anos e 54\% eram homens. 21 pacientes apresentaram critérios de doença grave, 9 deles necessitaram de ventilação mecânica. O NLR = 3 foi encontrado em 81\% (18/21) dos pacientes graves e em 33\% (36/110) dos pacientes leves (OR = 8,74, IC 95\% 2,74-27,86; p <0,001). A idade e a hipertensão foram associadas a doença grave. Obteve-se mortalidade de 7\% (9). Sete dos 9 pacientes que morreram apresentaram NLR = 3, com associação significativa entre mortalidade e NLR $=3(\mathrm{p}=0,03)$. Logo, o NLR pode ser usado em conjunto com outros preditores, como um marcador de prognóstico precoce no COVID-19, devido à sua acessibilidade e baixo custo.

No estudo de Ye et al. (2020), teve-se como objetivo avaliar a utilidade prognóstica das alterações dinâmicas do DDímero e NLR, especialmente o teste inicial na admissão e valor de pico durante a internação, em pacientes com COVID-19. Para isso, realizou-se um estudo retrospectivo, coletando dados de 349 pacientes hospitalizados com diagnóstico de infecção pelo COVID-19 no Hospital Pulmonar de Wuhan. Usou-se curvas ROC e análise de regressão de Cox para explorar o valor crítico (ponto de corte ideal associado ao índice de Youden) e o papel prognóstico das mudanças dinâmicas de D-dímero e NLR. Trezentos e quarenta e nove participantes foram incluídos neste estudo e a taxa de mortalidade dos pacientes com COVID-19 com diagnóstico laboratorial foi de 14,9\%. O valor inicial e de pico de D-Dímero e NLR em pacientes falecidos foram maiores estatisticamente em comparação com os sobreviventes ( $\mathrm{P}<0,001)$. Houve uma tendência de aumento mais significativa de D-Dímero e NLR durante a hospitalização nos pacientes falecidos, D-Dímero inicial e NLR foram menores do que os testes de pico (MD) -25,23, IC 95\%: - 31,81- -18,64, P < 0,001; (MD) -43,73, IC 95\%: -59,28- -31,17, P<0,001. O teste mostrou uma correlação mais forte entre os dias de hospitalização, PCT e pico D-Dímero do que o D-Dímero inicial. As áreas sob as curvas ROC dos testes de dímero D de pico e de NLR de pico foram maiores do que os testes iniciais (0,94 (IC de 95\%: 0,90-0,98) vs. 0,80 (IC de 95\%: 0,73-0,87); 0,93 (IC de 95\%: 0,90-0,96) vs. 0,86 (95\% CI: 0,82-0,91). O valor crítico do dímero D inicial, Dímero D de pico, NLR inicial e NLR de pico foi 0,73 mg / L, 3,78 mg / L, 7,13 e 14,31, respectivamente. 35 $(10,03 \%)$ pacientes foram intubados. Nos pacientes intubados, D-Dímero inicial e de pico e NLR foram muito maiores do que os pacientes não intubados ( $\mathrm{P}<0,001)$. O valor crítico do dímero D inicial, dímero D de pico, NLR inicial e NLR de pico no prognóstico de intubação foi de $0,73 \mathrm{mg} / \mathrm{L}, 12,75 \mathrm{mg} / \mathrm{L}, 7,28$ e 27,55. A análise de regressão multivariável de Cox mostrou que a idade (HR 1,04, IC 95\% 1,00-1,07, P = 0,01), o pico D-dímero (HR 1,03, IC 95\% 1,01-1,04, P <0,001) foram fatores prognósticos para COVID- Morte de 19 pacientes. Portanto, conclui-se que a proporção de D-dímero e NLR foi mais valioso durante o prognóstico de COVID-19. A tendência de aumento no D-Dímero e NLR, ou os resultados do teste superiores aos valores críticos podem indicar um risco de morte para participantes com COVID-19.

Buscando analisar a habilidade do NLR em predizer SDRA (Síndrome do Desconforto Respiratório Agudo), Ma et al. (2020), analisaram pacientes com diagnóstico de COVID-19 grave de 21 hospitais na província de Sichuan entre 16 de janeiro 
Research, Society and Development, v. 10, n. 16, e164101623482, 2021

(CC BY 4.0) | ISSN 2525-3409 | DOI: http://dx.doi.org/10.33448/rsd-v10i16.23482

e 15 de março foram incluídos na análise. O valor máximo de NLR, PLR, PCT e CRP durante os primeiros 3 dias após o diagnóstico de COVID-19 grave foi incluído na análise. COVID-19 grave e SDRA foram definidos de acordo com estudo anterior e definição de Berlim, respectivamente. A análise de regressão logística multivariada e a área sob a curva de característica de operação do receptor (ROC) foram utilizadas para analisar a habilidade do NLR em predizer SDRA. De um total de 81 pacientes definidos como COVID-19 grave, 44 foram diagnosticados como SDRA. A área sob a curva ROC para SDRA foi 0,71, 0,591, 0,494 e 0,625 para NLR, PLR, PCT e CRP, respectivamente. Usou-se a mediana como valor de corte para dividir os pacientes em dois grupos. O grupo NLR alto (NLR> 9,8) apresentou maior incidência de SDRA $(\mathrm{P}=0,005)$ e maior taxa de ventilação mecânica não invasiva $(\mathrm{P}=0,002)$ e invasiva $(\mathrm{P}=0,048)$. Além disso, definimos SDRA moderadagrave como pacientes com SDRA com índice de oxigenação inferior a 150. A área sob a curva ROC para SDRA moderadagrave foi 0,749, 0,660, 0,531 e 0,635 para NLR, PLR, PCT e CRP, respectivamente o valor de corte do NLR para SDRA moderada-grave é 11. Portanto, os dados obtidos revelaram que a NLR pode ser um biomarcador valioso para reconhecer pacientes COVID-19 graves com SDRA moderada a grave, o que facilitou os médicos a fornecer estratégias de suporte respiratório eficazes e descobrir rapidamente pacientes com SDRA moderada a grave que têm alta indicação para ECMO VV (Membrana de Oxigenação Extra Corpórea Veno-Venosa).

No estudo de Yang et al. (2020), objetivaram determinar o efeito do sexo, idade, PCR, contagem de leucócitos, NLR, LMR, PLR e comorbidades no tempo de internação de pacientes com pneumonia COVID-19. Para isso, foram investigados e comparados em laboratório a idade, a proporção de neutrófilos (NEU) para linfócitos (LYM) (NLR), a proporção de linfócitos para monócitos (MON), a proporção de plaquetas para linfócitos (PLR) e a proteína C reativa (CRP) de 93 pacientes com COVID-19 confirmados. A curva de característica de operação do receptor foi aplicada para determinar os limiares para cinco biomarcadores, e seus valores prognósticos foram avaliados por meio da curva de Kaplan-Meier e modelos de regressão multivariada COX. A idade média era 46,4 anos e 37 casos eram do sexo feminino. Um total de 27,8\% dos pacientes já haviam estado em Wuhan e 73,1\% haviam entrado em contato com pessoas de Wuhan. Febre (83,8\%) e tosse (70,9\%) foram os dois sintomas mais comuns. NLR elevado e idade foram significativamente associados à gravidade da doença. A análise logística binária identificou NLR elevado (risco de risco [HR] 2,46, intervalo de confiança de 95\% [IC] 1,98-4,57) e idade (HR 2,52, IC 95\% 1,65-4,83) como fatores independentes para desfecho clínico insatisfatório de COVID-19. NLR exibiu a maior área sob a curva em 0,841 , com a maior especificidade $(63,6 \%)$ e sensibilidade $(88 \%)$. Assim, concluiu-se que idade elevada e NLR podem ser considerados biomarcadores independentes para indicar resultados clínicos ruins.

No estudo de Chan et al. (2020), buscaram identificar a associação de NLR e PLR em relação à gravidade de COVID19. Para isso, foi realizada uma pesquisa bibliográfica usando EMBASE, MEDLINE e Google Scholar para estudos relatando o uso de NLR e PLR no COVID-19 publicados até 28 de abril de 2020. A meta-análise de efeitos aleatórios foi realizada para estimar a diferença média padrão (SMD) dos valores de NLR e PLR com intervalo de confiança de 95\% (IC) entre casos COVID-19 graves e não graves. Obteve-se um total de 20 estudos com 3.508 pacientes foram incluídos. Dezenove estudos relataram valores de NLR, enquanto cinco estudos relataram valores de PLR entre pacientes COVID-19 graves e não graves. Níveis mais elevados de NLR (SMD: 2,80, IC de 95\%: 2,12 - 3,48, P <0,00001) e PLR (SMD: 1,82, IC de 95\%: 1,03 - 2,61, P $<0,00001)$ ) foram observados em pacientes com doença grave em comparação com doença não grave. Portanto, conclui-se que NLR e PLR podem ser usados como marcadores prognósticos independentes da gravidade da doença em COVID-19.

No estudo de Ciccullo et al. (2020), no presente estudo objetivaram avaliar os preditores de evolução clínica. Para isso, foi analisado retrospectivamente um grupo de 74 pacientes com COVID-19 confirmado hospitalizados em nosso centro em março de 2020.Para cada paciente, foram coletados dados demográficos, história clínica, achados laboratoriais e medidas de tratamento durante a internação. De acordo com os sinais, sintomas, comorbidades e parâmetros clínicos na admissão e 
durante a hospitalização, os pacientes foram divididos em casos COVID-19 graves e não graves de acordo com as diretrizes italianas. A melhora clínica foi definida como a resolução da febre por $\geq 48$ horas a suspensão da suplementação de oxigênio.Testes paramétricos e não paramétricos foram usados, conforme apropriado, para comparar as alterações, e análises de regressão logística foram usadas para avaliar os preditores. Na análise multivariada, a melhora clínica foi prevista em idades mais jovens $(\mathrm{P}=0,040)$ e um NLR de $<3(\mathrm{P}=0,010)$ após ajuste para sexo, hipertensão pré-existente e sinais de pneumonia intersticial na admissão. A admissão à UTI foi, em vez disso, prevista por um NLR de > $4(\mathrm{P}=0,046)$ após ajuste para idade. A morte foi apenas prevista pela idade avançada $(P=0,047)$ após ajuste para NLR, sexo, hipertensão pré-existente e sinais de pneumonia intersticial na admissão hospitalar. No estudo atual, um NLR mais alto na admissão hospitalar foi associado a um desfecho mais grave: em particular, um NLR> 4 foi um preditor de admissão à UTI. Pacientes com doença grave apresentaram um NLR significativamente maior na admissão em comparação com pacientes com uma forma mais branda de COVID-19. Embora mais estudos com uma amostra maior sejam necessários para avaliar adequadamente esse assunto, o estudo atual mostra que a NLR pode ser um fator prognóstico útil, rápido e amplamente disponível no rastreamento precoce de doenças críticas em pacientes com COVID-19 confirmado.

No estudo de Wang et al. (2020), objetivaram analisar a robustez da proporção de neutrófilos para linfócitos CD4+ (NCD4LR) na previsão do tempo de conversão negativa (NCT) de SARS CoV-2 em pacientes com COVID-19. Para isso, foram realizadas análises univariadas e multivariadas para avaliar a independência de NCD4LR na previsão de NCT. A análise da curva de característica de operação do receptor (ROC) e a área sob a curva (AUC) foram usadas para avaliar a precisão do diagnóstico. Em comparação com pacientes com NCD4LR baixo, os pacientes com NCD4LR alto tinham uma idade mais avançada; maior incidência de febre, fadiga, desconforto no peito / falta de ar, avaliação mais grave da doença na admissão; níveis mais elevados de indicadores inflamatórios; baixos níveis de subconjuntos de linfócitos e um NCT mais longo. A análise multivariada também identificou NCD4LR como um fator de risco independente para NCT atrasado. A análise ROC mostrou que NCD4LR teve um melhor desempenho do que a proporção de neutrófilos para linfócitos na previsão da conversão negativa do vírus em 2 semanas (AUC $=0,772), 3$ semanas $(\mathrm{AUC}=0,710), 4$ semanas $(\mathrm{AUC}=0,728)$ ou 5 semanas $(\mathrm{AUC}=$ 0,815). Portanto, este estudo sugere que o NCD4LR é um biomarcador potencial e útil para prever o tempo de conversão negativa do vírus em pacientes com COVID-19. Além disso, devido ao valor de NCD4LR ser facilmente calculado, ele pode ser amplamente utilizado como um biomarcador clínico para a progressão da doença e desfechos clínicos em pacientes com COVID-19.

No estudo Seyit et al. (2020), objetivaram investigar e comparar os impactos prognósticos da proteína C reativa (PCR), contagem de leucócitos (leucócitos), razão de neutrófilos (NEU) para linfócitos (LYM) (NLR), plaquetas para relação de linfócitos (PLR), biomarcadores de largura de distribuição de glóbulos vermelhos (RDW) em casos COVID-19 confirmados em laboratório, bem como para explorar os biomarcadores diagnósticos mais úteis e valores de corte ideais em pacientes COVID-19. Para isso, um total de 233 pacientes foram admitidos no Departamento de Emergência (ED) do Hospital Universitário de Pamukkale durante dois meses (março-abril de 2020) e foram submetidos a SARS-CoV-2 PCR (Reação em Cadeia da Polimerase), hemograma completo (CBC) e testes de PCR em sequência devido a reclamações do COVID-19. Os resultados laboratoriais e os achados demográficos foram coletados do sistema de gestão de saúde pública retrospectivamente. Os pacientes com teste Sars-CoV 2 PCR positivo juntamente com dados de internação também foram registrados. A PCR ( $p=$ 0,0001), lactato desidrogenase $(\mathrm{LDH})(\mathrm{p}=0,038)$, PLR $(\mathrm{p}=0,0001)$ e NLR $(\mathrm{p}=0,001)$ permaneceram significativamente maiores nos pacientes com teste de PCR positivo para Sars CoV-2. Em contraste, os níveis de eosinófilos (p = 0,0001), linfócitos $(\mathrm{p}=0,0001)$ e plaquetas $(\mathrm{p}=0,0001)$ foram calculados como significativamente mais elevados em pacientes SARSCoV-2 negativos. Portanto, os resultados obtidos, os níveis de CRP, LDH, PLR e NLR permaneceram significativamente mais 
elevados em pacientes COVID-19 positivos, enquanto os níveis de eosinófilos, linfócitos e plaquetas estavam significativamente elevados em pacientes COVID19 negativos.

No estudo de Liu et. al (2020), teve- se como objetivo rastrear o fator preditivo mais útil para doenças críticas causadas por COVID-19. Para isso, o estudo envolveu prospectivamente 61 pacientes com infecção por COVID-19 como uma coorte de derivação e 54 pacientes como uma coorte de validação. O fator preditivo para doença crítica foi selecionado por meio da análise de regressão LASSO. Um nomograma baseado em indicadores laboratoriais não específicos foi construído para prever a probabilidade de doença crítica. A proporção de neutrófilos para linfócitos (NLR) foi identificada como um fator de risco independente para doença crítica em pacientes com infecção por COVID-19. O NLR teve uma área sob a característica de operação do receptor de 0,849 (intervalo de confiança de 95\% [CI], 0,707 a 0,991) na coorte de derivação e 0,867 (IC 95\% 0,747 a 0,944) na coorte de validação, as curvas de calibração se ajustaram bem, e as curvas de decisão e impacto clínico mostraram que o NLR teve um benefício líquido padronizado alto. Além disso, a incidência de doença crítica foi de $9,1 \%$ (1/11) para pacientes com idade $\geq 50$ e tendo um NLR $<3,13$, e $50 \%(7 / 14)$ dos pacientes com idade $\geq 50$ e NLR $\geq$ 3,13 foram preditos para desenvolver doença crítica. Com base na estratificação de risco de NLR de acordo com a idade, este estudo desenvolveu um processo de gerenciamento de pneumonia COVID-19. Logo, descobriu-se que a NLR é um fator preditivo para a previsão em estágio inicial de pacientes infectados com COVID-19 que têm probabilidade de desenvolver doença crítica. Prevê-se que os pacientes com idade $\geq 50$ e NLR $\geq 3,13$ desenvolvam doença crítica e, portanto, devem ter acesso rápido a uma unidade de terapia intensiva, se necessário.

No estudo Jimeno et al. (2020), teve- se como objetivo um levantamento da hipótese de que o NLR, como um marcador de disfunção endotelial, pode ser útil na identificação de pacientes com mau prognóstico em casos de COVID-19 hospitalizados. Para isso, um estudo observacional retrospectivo realizado no Hospital Universitário HM Puerta del Sur, Madrid, Espanha, que incluiu 119 pacientes com COVID-19 de 1 de março a 31 de março de 2020. Os pacientes foram categorizados de acordo com o Grupo de Especialistas em P \& D da OMS. Quarenta e cinco (12,1\%) pacientes apresentaram insuficiência respiratória aguda grave, necessitando de suporte respiratório. Quarenta e sete $(12,6 \%)$ pacientes morreram. Aqueles com resultados piores eram mais velhos $(\mathrm{P}=0,002)$ e apresentavam NLR significativamente maior na admissão $(\mathrm{P}=$ 0,001), maior aumento no NLR de pico ( $\mathrm{P}<0,001)$ e maior velocidade de aumento de NLR ( $\mathrm{P}=0,003)$ em comparação com pacientes de acompanhamento. Em uma regressão logística multivariável, idade, doença cardiovascular e proteína C reativa na admissão e Pico de NLR foram significativamente associados com óbito. Logo, o NLR é um parâmetro facilmente mensurável, disponível, com boa relação custo-benefício e confiável, cujo monitoramento contínuo pode ser útil para o diagnóstico e tratamento da COVID-19.

No estudo Kong et al. (2020) teve-se como objetivo investigar a associação entre diferentes dados laboratoriais (incluindo subconjuntos de linfócitos e biomarcadores inflamatórios) e características clínicas de pacientes hospitalizados com infecção por COVID-19 leve e grave para revelar um fator prognóstico potencialmente útil associado à morbidade grave. Para isso, este estudo foi retrospectivo unicêntrico entre pacientes atendidos no Hospital Central de Wuhan, hospital específico para o tratamento de pacientes com COVID-19. A análise do subconjunto de linfócitos foi realizada nos pacientes incluídos na análise final e internados de 27 de janeiro de 2020 a 9 de março de 2020. O diagnóstico clínico de pneumonia viral foi inicialmente baseado em seus sintomas clínicos, incluindo febre, tosse ou doença respiratória e alterações típicas de TC de tórax. A condição foi considerada COVID-19 do tipo grave quando um dos seguintes critérios estava presente: (1) Desconforto respiratório com frequência respiratória> 30 / min; (2) saturação de oxigênio $\leq 93 \%$ em repouso; ou (3) pressão parcial de oxigênio no sangue arterial $(\mathrm{PaO} 2)$ /concentração de oxigênio $(\mathrm{FiO} 2) \leq 300 \mathrm{mmHg}(1 \mathrm{mmHg}=0,133 \mathrm{kPa})$. Se o acompanhamento desses casos revelou progressão para casos com necessidade de internação em unidade de terapia intensiva 
(UTI), o prognóstico foi considerado muito ruim. lista as características demográficas e clínicas da infecção por COVID-19. Entre os 210 pacientes com diagnóstico de COVID-19, 87 (41,4\%) foram categorizados no grupo grave e 123 (58,6\%) no grupo leve na admissão. No grupo grave, 38 (43,7\%) evoluíram para UTI ou até óbito; no grupo leve, apenas $1(0,8 \%)$ evoluiu para um caso crítico. Em comparação com os pacientes do grupo leve, os pacientes do grupo grave eram mais velhos $(67,9 \pm$ $12,3$ vs. $53,2 \pm 15,6, \mathrm{P}=0,005)$, principalmente os maiores de 70 anos $(39,1 \%)$. Não foi encontrada diferença significativa na proporção de mulheres entre o grupo grave (50,5\%) e o grupo leve. Um total de $72(82,8 \%)$ casos graves e $82(66,7 \%)$ casos leves apresentaram febre, e uma diferença significativa na temperatura corporal foi determinada entre os dois grupos. Em comparação com os casos leves, os casos graves foram mais propensos a experimentar leve falta de ar ( P <0,001), mialgia ( $\mathrm{P}$ $=0,009)$, fadiga $(\mathrm{P}=0,011)$ e congestão torácica $(\mathrm{P}<0,001)$. Enquanto isso, $99(47,1 \%)$ pacientes tinham pelo menos uma comorbidade subjacente, e a proporção de casos graves com comorbidade subjacente era maior do que a de casos leves $(65,5 \%$ vs. $34,1 \%, \mathrm{P}<0,001)$. A comparação entre os casos graves e os casos leves indicou diferenças significativas em diabetes $(\mathrm{P}=$ 0,004), hipertensão ( $\mathrm{P}<0,001)$, doença renal crônica ( $\mathrm{P}=0,024)$ e tumor ( $\mathrm{P}=0,007)$, mas não em doença cardiovascular, hiperlipidemia , tuberculose e doença pulmonar obstrutiva crônica (DPOC). Portanto, COVID-19 pode afetar principalmente os linfócitos, especialmente os linfócitos T. NLR foi um fator de risco precoce que afeta o prognóstico de pacientes com doença COVID-19 grave. Pacientes com um NLR mais alto devem ser internados em uma ala de isolamento com monitoramento respiratório e cuidados de suporte.

No estudo Lian et al. (2020) objetivou-se investigar a correlação da razão neutrófilos / linfócitos (NLR) com doença crítica em pacientes idosos com COVID-19 e avaliar o poder prognóstico do NLR na admissão. Para isso, 232 pacientes com COVID-19, com idade $\geq 60$ anos, na província de Zhejiang de 17 de janeiro a 3 de março de 2020. Os resultados primários foram avaliados até 13 de abril. A regressão de Cox foi realizada para fatores prognósticos. Vinte e nove (12,5\%) os pacientes evoluíram para doenças críticas. Idade, falta de ar, comorbidades incluindo hipertensão, doença cardíaca e pulmonar obstrutiva crônica doença, NLR mais alto, níveis mais baixos de albumina e múltiplas manchas e vidro fosco opacidade foram associadas à progressão. Na análise multivariada, idade mais avançada (razão de risco [HR] 1,121, intervalo de confiança [CI] 1,0701,174, P <0,001), doença cardíaca (HR 2,587, CI 1,156-5,787, P = 0,021), NLR superior (HR 1,136, CI 1,094-1,180, P $<0,001$ ), e manchas múltiplas e vidro fosco opacidade (HR 4.518, CI 1.906-10.712, P <0,001) permaneceu como preditores de doenças críticas. O NLR foi independentemente associado à progressão para doença crítica; a relação foi significativa e graduada (HR: 1,16 por unidade; IC 95\%: 1,10-1,22; P para tendência <0,001). Portanto, a NLR pode ser adotada como uma ferramenta de prognóstico para auxiliar provedores de saúde que prevêem os resultados clínicos de pacientes mais velhos que sofrem do COVID-19.

Na pesquisa de Cai et al. (2021), buscou-se a validação da relação Neutrófilos/Leucócitos (NLR) como um indicador que possa auxiliar na tomada de decisão clínica quanto ao início do tratamento com corticosteróides em indivíduos com Covid19. Os participantes do estudo foram indivíduos com COVID-19, internados entre 30 de dezembro de 2019 e 17 de abril de 2020, em 21 hospitais em Hubei, China. Um total de 12.862 indivíduos com COVID-19 foram incluídos neste estudo, sendo que 25,3\% deles estiveram em terapia com uso de corticosteróides. Descobriu-se que valores de NLR > 6,11 na admissão hospitalar discriminavam um maior risco de mortalidade. O tratamento com corticosteróides nesses indivíduos foi associado a um menor risco de mortalidade por todas as causas em 60 dias. Por outro lado, em indivíduos com um NLR $\leq 6,11$ ou com diabetes tipo 2, o tratamento com corticosteróides não foi associado à redução da mortalidade, mas sim ao aumento do risco de hiperglicemia e infecções. O estudo conclui que a obtenção dos valores de NLR na admissão é um parâmetro altamente prático e aplicável para a estratificação de risco, de modo que indivíduos com Covid-19 em estado grave (NLR>6,11), podem se beneficiar do tratamento de corticosteróides em baixas doses, evidenciado por uma redução da mortalidade. Já em indivíduos 
com baixo estado inflamatório (NLR $\leq 6,11$ ) ou DM2 preexistente, o uso de corticosteróides deve ser feito com cautela, tendo em vista os efeitos adversos significativos e a ausência de melhora perceptível nos desfechos clínicos.

No estudo de Téllez et al. (2020), buscou-se avaliar a eficácia da relação linfócitos/neutrófilos (LNR) e neutrófilos/monócitos (NMR) como preditores de mortalidade na admissão em pacientes adultos com infecção grave por SARS-CoV-2. Um total de 54 pacientes mexicanos adultos, com COVID-19, que preencheram os critérios de hospitalização, foram inscritos de modo retrospectivo na pesquisa. Eles foram acompanhados diariamente até a alta hospitalar ou morte e, em seguida, atribuídos a grupos de sobrevivência ou não-sobrevivência. Em comparação com o grupo não sobrevivente, no grupo sobrevivente o LNR diminui cerca de quatro vezes, enquanto o NMR aumentou duas vezes. Valores de LNR $\leq 0,088$ levaram a uma mortalidade hospitalar prevista com uma sensibilidade de $85 \%$ e uma especificidade de 74,19\%. Já valores de RMN $\geq$ 17,75 foram considerados os melhores fatores de risco independentes para mortalidade, com uma sensibilidade de $89,47 \%$ e uma especificidade de $80 \%$. Este estudo demonstra que um LNR menor que 0,088 e um NMR maior que 17,75 no momento da admissão, podem prever com precisão a mortalidade hospitalar de pacientes com COVID-19 grave. O estudo também destaca que o NMR é significativamente mais sensível e específico em pacientes com COVID-19 grave, que atendem os critérios de hospitalização. Assim, o estudo conclui que pela simples divisão da contagem de neutrófilos pela contagem de monócitos, ou a contagem de linfócitos pela contagem de neutrófilos, no momento da admissão hospitalar, os médicos podem ter preditores baratos, rápidos e confiáveis para morte intra-hospitalar em pacientes com Covid-19.

No estudo de Xisheng Yan et al. (2020), buscaram investigar se a NLR (Relação neutrófilo/linfócito) é um fator prognóstico em pacientes com COVID-19. Para isso foi realizado um delineamento, em que uma coorte de pacientes com COVID-19 internados no Hospital Tongren da Universidade de Wuhan, de 11 de janeiro a 3 de março de 2020, foi analisada retrospectivamente. O NLR foi calculado pela divisão da contagem de neutrófilos pela contagem de linfócitos, cujos valores foram medidos no momento da admissão. Pacientes com malignidade hematológica foram excluídos da pesquisa. Foi realizada uma análise logística multivariada e um total de 1.004 pacientes com COVID-19 foram incluídos neste estudo. O valor de NLR foi maior no grupo de não sobreviventes (mediana: 49,06; intervalo interquartil [IQR]: 25,71-69,70) do que no grupo de sobreviventes (mediana: 4,11; IQR: 2,44-8,12; P <0,001). Na análise de regressão logística multivariada, valores de NLR maiores que 11,75 estavam significativamente correlacionados com todas as causas de mortalidade hospitalar (odds ratio $=$ 44,351; intervalo de confiança de $95 \%=4,627-425,088)$. Portanto, o NLR parece ser um biomarcador prognóstico significativo de resultados em pacientes gravemente enfermos com COVID-19.

No estudo conduzido por Xu et al. (2020), pretendeu-se explorar se os fatores de inflamação basal, como a relação neutrófilo linfócito (NLR), proteína C reativa (PCR) e procalcitonina (PCT) estariam associados a um risco aumentado de morte em pacientes com COVID-19. O estudo retrospectivo realizado envolveu um total de 76 pacientes com teste confirmado para COVID-19, entre 17 de janeiro e 2 de março de 2020, de modo que destes, 17 pacientes evoluíram para óbito. Foi revisado o prontuário eletrônico dos pacientes, coletando os dados necessários como valores de PCT, PCR e NLR. Os resultados mostraram que $\mathrm{PCT} \geq 0,10 \mathrm{ng} / \mathrm{mL}$ e CRP $\geq 52,14 \mathrm{mg} / \mathrm{L}$ exibiram riscos crescentes para mortalidade, enquanto valores de NLR maiores que 3,59 não foram considerados fatores de risco independentes para óbito. O estudo conclui que valores aumentados de PCT e PCR podem ser considerados preditores independentes de sobrevida em pacientes com COVID19, mas o NLR elevado não parece útil para discriminar a morte nesses pacientes. No entanto, o tamanho da amostra pode ser pouco representativo, necessitando de mais estudos futuros.

Na pesquisa de Zhang et al. (2020), objetivou-se alcançar a fenotipagem imunológica de pacientes com COVID-19 com base na resposta IgG tardia e na relação NLR, buscando determinar a gravidade da doença e o resultado clínico. Nesse estudo foram incluídos 222 pacientes com COVID-19, em um centro em Wuhan, de modo que os valores de IgG e a relação 
NLR foram caracterizadas de acordo com os diferentes tipos de gravidade e desfecho da doença. Os casos graves foram mais frequentemente encontrados em pacientes com níveis elevados de $\operatorname{IgG}$ em comparação com aqueles com níveis baixos (p = 0,008) enquanto a taxa de gravidade para pacientes com valores de IgG e NLR elevados foi de 72,3 (p < 0,0001). As taxas de recuperação para pacientes com NLR-alto/IgG-alto, NLR-alto/IgG-baixo, NLR-baixo/IgG-alto e NLR-baixo/IgG-baixo foram de 58,8\% (20/34), 68,8\% (11/16), 80,0\% (4/5 ) e 100\% (12/12), respectivamente ( $\mathrm{p}=0,0592)$, enquanto os óbitos ocorreram apenas nos casos de NLR-alto/IgG-alto e NLR-alto/IgG-baixo. O estudo conclui que a gravidade do COVID-19 está associada ao aumento da resposta de IgG e uma fenotipagem da resposta imune com base nos níveis de IgG tardia e da relação NLR poderia atuar como uma ferramenta complementar simples para discriminar entre pacientes COVID-19 graves e não graves e prever ainda mais seus resultados clínicos.

O artigo de Nalbant et al. (2021) objetivou investigar parâmetros do hemograma, como NLR, razão plaquetas linfócitos (PLR), proteína C reativa (PCR) e outros biomarcadores inflamatórios e suas associações com o COVID-19. Participaram da pesquisa 80 indivíduos hospitalizados, que realizaram o teste PCR para o coronavírus e foram separados em um grupo com resultado negativo e outro grupo com resultado positivo, o qual envolveu 54 participantes (67,5\% do total). No grupo covid-19 +, os valores de NLR, PLR e CRP estavam significantemente aumentados, e a contagem de linfócitos estava menor. A Sensibilidade, especificidade, VPP, VPN, valores LR +, LR-, e a prevalência de COVID-19 para valores de NLR $\geq$ 2,4 foi de $69,01 \%, 65,40 \%, 80 \%, 50 \%, 1,98,0,48$ e $67,5 \%$, respectivamente. O estudo conclui que, o NLR estava significativamente elevado em pacientes com COVID-19 e também forneceu um ponto de corte, mostrando que pacientes com NLR $\geq 2,4$ foram 20,5 vezes mais prováveis em ter COVID-19 em comparação a pacientes cujo NLR foi $\leq 2,4$. Esse estudo afirma que altos níveis de NLR e febre são biomarcadores independentes para pacientes com Covid-19.

No estudo de Wang et al. (2020), tiveram como objetivo explorar se a proporção de neutrófilos / linfócitos (NLR) e a proporção de plaquetas / linfócitos (PLR) estão associadas ao desenvolvimento de óbito em pacientes com COVID-19. Para isso, um total de 131 pacientes com diagnóstico de COVID-19 de 13 de fevereiro de 2020 a 14 de março de 2020 em um hospital em Wuhan designado para o tratamento de COVID-19 foram incluídos no estudo atual. Esses 131 pacientes tinham uma idade mediana de 64 anos (intervalo interquartil: 56-71 anos). Além disso, entre esses pacientes, 111 (91,8\%) pacientes tiveram alta e $12(9,2 \%)$ pacientes morreram no hospital. A análise combinada revelou que o NLR na admissão foi significativamente elevado para não sobreviventes, quando comparado aos sobreviventes (P <0,001). O NLR de 3,338 foi associado à mortalidade por todas as causas, com uma sensibilidade de 100,0\% e uma especificidade de 84,0\% (área sob a curva (AUC): 0,963, intervalo de confiança de 95\% (IC) 0,911-1.000; $\mathrm{P}<0,001)$. Em vista do pequeno número de mortes (n = 12) no estudo atual, NLR de 2,306 pode ter valor potencial para ajudar os médicos a identificar pacientes com COVID-19 grave, com uma sensibilidade de 100,0\% e uma especificidade de 56,7\% (AUC: 0,729, IC 95\% 0,563-0,892; P = 0,063). O NLR foi significativamente associado ao desenvolvimento de óbito em pacientes com COVID-19. Portanto, concluiu-se que o NLR é um biomarcador útil para prever a mortalidade por todas as causas de COVID-19.

No estudo de Liu et al. (2020), objetivaram explorar um nomograma fácil de usar e um modelo para fazer a triagem de pacientes em categorias de risco para determinar a probabilidade de desenvolver uma doença crítica. Para isso, foi realizado um estudo de coorte retrospectivo. Extraíram dados de 84 pacientes com COVID-19 confirmado em laboratório de um hospital designado. $\mathrm{O}$ endpoint primário foi o desenvolvimento de doença grave / crítica no prazo de 7 dias após a admissão. Fatores preditivos deste endpoint foram selecionados pelo modelo de regressão LASSO Cox. Um nomograma foi desenvolvido com base em variáveis selecionadas. O desempenho preditivo do nomograma derivado foi avaliado por curvas de calibração e curvas de decisão. Além disso, os desempenhos preditivos das variáveis individuais e combinadas em estudo foram avaliados por curvas de características de operação do receptor. O modelo desenvolvido também foi testado em um conjunto de 
Research, Society and Development, v. 10, n. 16, e164101623482, 2021

(CC BY 4.0) | ISSN 2525-3409 | DOI: http://dx.doi.org/10.33448/rsd-v10i16.23482

validação separado com 71 pacientes COVID-19 confirmados em laboratório. Nenhum dos 84 pacientes internados foi perdido para acompanhamento neste estudo retrospectivo. O desfecho primário ocorreu em 23 pacientes internados (27,4\%). A razão neutrófilos / linfócitos (NLR) e a proteína C reativa (PCR) foram selecionadas como os fatores prognósticos finais. Um nomograma foi desenvolvido com base no NLR e CRP. A curva de calibração e a curva de decisão indicaram que o modelo de nomograma construído era clinicamente útil. As AUCs para NLR, CRP e Índice combinado em ambos os conjuntos de treinamento e validação foram de 0,685 (IC de 95\%: 0,574-0,783), 0,764 (IC de 95\%: 0,659-0,850), 0,804 (IC de 95\%: 0,7020,883) e 0,881 (IC 95\%: 0,782-0,946), respectivamente. Logo, os resultados demonstraram que o nomograma e o índice combinado calculado a partir do NLR e PCR são preditores potenciais e confiáveis do prognóstico do COVID-19 e podem triar os pacientes no momento da admissão.

No estudo de Qun et al. (2020), objetivaram conduzir uma análise aprofundada para esclarecer alguns dos mecanismos patológicos da doença e identificar medidas simples para prever sua gravidade precocemente. Para isso, um total de 230 pacientes com COVID-19 não leve foram recrutados e informações sobre suas características clínicas, citocinas inflamatórias e subconjuntos de linfócitos $\mathrm{T}$ foram coletadas. Fatores de risco para gravidade foram analisados por regressão logística binária, e as associações das proporções de neutrófilos para linfócitos (N / LRs) com gravidade da doença, curso da doença, classificação CT, citocinas inflamatórias e subconjuntos de linfócitos T foram avaliadas. Os resultados mostraram que os N / LRs estavam intimamente relacionados à interleucina (IL) -6 e IL-10 (P <0,001, P = 0,024) e aos linfócitos T CD3 + e $\mathrm{CD} 8+(\mathrm{P}<0,001, \mathrm{P}=0$,046) Em particular, os $\mathrm{N} / \mathrm{LRs}$ foram positivamente correlacionados com a gravidade e o curso da doença $\mathrm{P}=0,021, \mathrm{P}<0,001)$. Em comparação com os valores no primeiro teste após a admissão, IL-6 e IL-10 diminuíram e aumentaram significativamente, respectivamente, a partir do último teste antes da alta $(\mathrm{P}=0,006, \mathrm{P}<0,001)$. Mais importante, por meio de regressão logística binária, descobriram que sexo masculino, doenças subjacentes (como doença cardiovascular), pulso e $\mathrm{N} / \mathrm{LRs}$ estavam intimamente relacionados à gravidade da doença $(\mathrm{P}=0,004, \mathrm{P}=0,012, \mathrm{P}=0,013, \mathrm{P}=0,028)$. Portanto, como um marcador rápido e conveniente de inflamação, os N / LRs podem predizer o curso da doença e o nível de gravidade de COVID-19 não leve; sexo masculino, doença cardiovascular e pulso também são fatores de risco para a gravidade de COVID-19 não leve.

No estudo de Liu et al. (2020), objetivaram identificar os preditores críticos que podem avaliar efetivamente as condições da doença de pacientes com COVID-19, analisando as características clínicas e achados laboratoriais de pacientes com infecção por SARS-CoV-2. Para isso, todos os pacientes consecutivos ( $n=294)$ com infecção confirmada de SARS-CoV2 internados no Hospital Geral do Comando do Teatro Central do PLA de 6 a 21 de fevereiro de 2020 foram inscritos. Esses pacientes foram divididos em grupo grave e grupo não grave de acordo com a gravidade da doença durante a internação. $\mathrm{O}$ valor médio da relação neutrófilos / linfócitos (NLR) dos pacientes graves foi dramaticamente maior do que o dos pacientes não graves (10,4 vs 2,6; P <0,001). O valor de NLR igual a 5 foi um valor limite digno de referência, porque mais de $80 \%$ dos pacientes graves tiveram um valor de NLR maior que 5 e mais de $80 \%$ dos pacientes não graves tiveram um valor de NLR menor que 5. O valor de NLR desses COVID-19 os pacientes foram positivamente e respectivamente correlacionados com os valores da proteína $C$ reativa $(R=0,5921, P<0,001)$, lactato desidrogenase $(R=0,4509, P<0,001)$, procalcitonina $(R=$ 0,5504, $\mathrm{P}<$. 001), fibrinogênio $(\mathrm{R}=0,4710, \mathrm{P}<0,001)$ e dímeros $\mathrm{D}(\mathrm{R}=0,4425, \mathrm{P}<0,001)$. No entanto, o valor de NLR foi meramente e positivamente correlacionado com o valor de interleucina-6 $(\mathrm{R}=.3594, \mathrm{P}<.05)$. Logo, a proporção neutrófilos / linfócitos é um preditor crítico para avaliação da gravidade da doença em pacientes com COVID-19 e tem estreita relação com os indicadores laboratoriais relacionados às condições da doença.

No estudo de Pimentel et al. (2020), objetivaram destacar a importância da relação neutrófilos / linfócitos em pacientes infectados pela pandemia de COVID-19. Para isso, reuniu os principais pontos de diversos estudos envolvendo o 
Research, Society and Development, v. 10, n. 16, e164101623482, 2021

(CC BY 4.0) | ISSN 2525-3409 | DOI: http://dx.doi.org/10.33448/rsd-v10i16.23482

NRL. A alta proporção de neutrófilos-linfócitos (NLR) leva a complicações graves nos pacientes infectados com COVID-19, como fadiga, tosse seca, febre, pneumonia, infecção respiratória aguda, insuficiência de órgãos e baixa qualidade de vida. Por outro lado, a manutenção das concentrações sanguíneas de NLR pode melhorar a resposta ao comprometimento do sistema imunológico. Portanto, o NLR é um marcador de inflamação sistêmica útil para a triagem de pacientes infectados com COVID-19 e pode ser usado como um indicador útil de um mau prognóstico no momento inicial da hospitalização.

No estudo de Eslamijouybari et al. (2020), objetivaram comparar os índices do hemograma (hemograma completo) entre pacientes com COVID-19 e o grupo controle, e avaliar a relação desses índices com o prognóstico do COVID-19. Para isso, pacientes COVID-19 (confirmados por PCR ou tomografia computadorizada) que visitaram o Hospital Imam em Sari foram selecionados neste estudo de caso-controle. O grupo controle foi selecionado da população da coorte Tabari pareada com o grupo de caso em termos de gênero e idade. CBC, proporção de neutrófilos para linfócitos (NLR), proporção de plaquetas para linfócitos (PLR) e o resultado da doença (no grupo de caso) foram avaliados neste estudo. O número de participantes foi de 527 em ambos os grupos de caso e controle, dos quais 232 (44\%) eram mulheres em cada braço. A contagem de plaquetas, contagem de linfócitos e concentração de hemoglobina também foram maiores no grupo controle $(\mathrm{P}=$ 0,000). NLR e PLR foram significativamente maiores em pacientes com COVID-19 em comparação com o grupo controle (P $=0,000)$. NLR teve uma relação significativa com a gravidade da doença. NLR foi duas vezes maior nos pacientes que morreram de COVID-19 do que aqueles que se recuperaram $(\mathrm{P}=0,000)$. A análise da curva ROC para valores diagnósticos de NLR e PLR mostrou que as áreas sob as curvas ROC para NLR e PLR foram 0,703 (IC 95\%: 0,64-0,76) e 0,535 (IC 95\%: 0,46-06), respectivamente. Portanto, NLR pode ser usado como um marcador prognóstico para COVID-19, dada a diferença significativa de NLR entre aqueles que morreram e se recuperaram de COVID-19.

No estudo de Mousavi-Nasab et al. (2020), objetivaram investigar a relação neutrófilos / linfócitos (NLR) com proteína C reativa para identificar potenciais preditores clínicos e analisar diferenças entre pacientes com COVID-19 grave e não grave. Para isso, foi analisada uma população de pacientes com COVID-19 encaminhados ao Loghman Hospital em Teerã. Os dados da linha de base dos exames laboratoriais, incluindo os níveis de NLR e CRP, foram coletados. A análise de Pearson foi usada para avaliar a relação independente entre o NLR com a gravidade da doença e os níveis de PCR. Os casos de COVID-19 compreendiam 14 (20\%) pacientes com doença grave e 56 (80\%) com infecção não grave. Os valores médios de WBC, NEU, LYM e NLR dos pacientes graves foram significativamente maiores do que os dos pacientes não graves. Quarenta e seis pacientes $(65,7 \%)$ tiveram NLR> 1, e os demais pacientes tiveram NLR <1. Os níveis plasmáticos de PCR foram maiores nos casos graves do que nos não graves, e essa diferença foi significativa. Os resultados mostraram que o NLR foi positivamente correlacionado com os níveis de PCR $(\mathrm{R}=0,23)$ e negativamente correlacionado com $\mathrm{WBC}(\mathrm{R}=-0,38)$. CRP (AUC = 0,97, IC de 95\%: 0,95-0,99) e NLR (AUC = 0,87, IC de 95\%: 0,81-0,93) tiveram uma precisão muito boa em prever a gravidade da doença COVID-19. Portanto, os resultados deste estudo indicaram que a integração de NLR e CRP pode levar a melhores previsões e é recomendado como um valioso marcador precoce para avaliar o prognóstico e avaliar a gravidade dos sintomas clínicos em pacientes com COVID-19.

No estudo de Moradi et al. (2020), objetivaram avaliar o potencial preditivo do NRL em termos de mortalidade em COVID-19. Para isso, foram incluídos nesse estudo pacientes internados no hospital Imam Reza, afiliado à Mashhad University of Medical Sciences, Mashhad, Irã, de março a junho de 2020, com resultados de RT-PCR positivos para SARSCoV-2. A análise de sobrevivência de Kaplan-Meier e o modelo de risco proporcional de Cox foram usados para estimar, respectivamente, a mortalidade em um mês desde a admissão e determinar os fatores associados à mortalidade em um mês. Neste estudo de coorte retrospectivo, foram incluídos 219 pacientes (137 homens e 82 mulheres (média de idade 58,2 \pm 16 e 57 $\pm 17,3$ anos, respectivamente)). Hipertensão, doença isquêmica do coração e diabetes foram, respectivamente, as comorbidades 
mais comuns. Entre esses pacientes, 63 pacientes foram admitidos na UTI e 31 óbitos ocorreram durante o acompanhamento de um mês. Com relação à saturação capilar periférica média de oxigênio (SpO 2), 142 pacientes apresentaram SpO $2 \leq 90 \%$. Com base em nossa análise, idade avançada e aumento da proporção de neutrófilos para linfócitos (NLR) e contagem de leucócitos (leucócitos) foram associados a risco aumentado de mortalidade em um mês. Pacientes com SpO $2 \leq 90 \%$ tiveram um aumento de 3,8 vezes no risco de morte em um mês em comparação com aqueles com SpO 2 > 90\%, embora a diferença não tenha atingido um nível significativo. Portanto, a análise multivariada introduziu idade, contagem de leucócitos e NLR como preditores de mortalidade em um mês em pacientes com COVID-19.

No estudo de Seyit et al. (2021) teve como objetivo nvestigar e comparar os impactos prognósticos da proteína C reativa (PCR), contagem de leucócitos (leucócitos), razão de neutrófilos (NEU) -para-linfócitos (LYM) (NLR), plaquetas razão para linfócitos (PLR), biomarcadores de largura de distribuição de glóbulos vermelhos (RDW) em casos COVID-19 confirmados em laboratório, bem como para explorar os biomarcadores diagnósticos mais úteis e valores de corte ideais em pacientes COVID-19. Para isso, um total de 233 pacientes foram admitidos no Departamento de Emergência (ED) do Hospital Universitário de Pamukkale durante dois meses (março-abril de 2020) e foram submetidos a SARS-CoV-2 PCR (Reação em Cadeia da Polimerase), hemograma completo (CBC) e PCR testes em sequência devido a reclamações do COVID-19. Os resultados laboratoriais e os achados demográficos foram coletados do sistema de gestão de saúde pública retrospectivamente. Os pacientes com teste de PCR Sars CoV-2 positivo juntamente com dados de internação também foram registrados. A PCR (p $=0,0001)$, lactato desidrogenase $(\mathrm{LDH})(\mathrm{p}=0,038), \operatorname{PLR}(\mathrm{p}=0,0001)$ e NLR $(\mathrm{p}=0,001)$ permaneceram significativamente maiores nos pacientes com teste de PCR positivo para Sars CoV-2. Em contraste, os níveis de eosinófilos ( $\mathrm{p}=0,0001)$, linfócitos $(\mathrm{p}=0,0001)$ e plaquetas $(\mathrm{p}=0,0001)$ foram calculados como significativamente mais elevados em pacientes Sars CoV-2 negativos. Diante dos resultados obtidos, os níveis de PCR, LDH, PLR e NLR permaneceram significativamente mais elevados nos pacientes COVID-19 positivos, enquanto os níveis de eosinófilos, linfócitos e plaquetas foram significativamente elevados nos pacientes COVID-19 negativos.

No estudo de Yufei et al. (2020), objetivaram investigar o valor da detecção combinada da razão neutrófilos / linfócitos (NLR) e do nível de proteína C reativa (PCR) no diagnóstico de COVID-19. Para isso, um total de 191 pacientes com COVID-19 foram recrutados no Terceiro Hospital de Wuhan de 21 de janeiro de 2020 a 20 de fevereiro de 2020.50 voluntários saudáveis foram selecionados aleatoriamente como o grupo de controle. Idade, sexo, contagem de leucócitos (WBC), PCR, porcentagem de linfócitos e NLR foram extraídos. As características clínicas quantitativas e os valores laboratoriais foram comparados entre os grupos. Fatores de risco e curvas de características de operação do receptor (ROC) para COVID-19 foram analisados. Descobriu-se que o NLR e a PCR foram maiores, enquanto a porcentagem de linfócitos foi menor em pacientes com COVID-19 do que em controles saudáveis. Entre os pacientes com COVID-19 confirmado, o NLR e a PCR do grupo moderado foram menores do que os dos pacientes graves (grupos grave, crítico e óbito), e o percentual de linfócitos do grupo moderado foi maior do que o do grupo crítico e óbito. Não houve diferenças significativas no WBC entre todos os grupos. A análise de regressão logística mostrou que o NLR, a PCR e a porcentagem de linfócitos foram fatores de risco independentes para COVID-19. A AUC da determinação combinada de NLR e CRP foi de 0,863, que foi maior do que a de NLR, PCR, WBC e porcentagem de linfócitos (AUC: 0,835, 0,775, 0,416 e 0,749, respectivamente). A análise de regressão logística mostrou que o NLR, a PCR e a porcentagem de linfócitos foram fatores de risco independentes para COVID-19. A AUC da determinação combinada de NLR e CRP foi de 0,863, que foi maior do que a de NLR, PCR, WBC e porcentagem de linfócitos (AUC: 0,835, 0,775, 0,416 e 0,749, respectivamente). A análise de regressão logística mostrou que o NLR, a PCR e a porcentagem de linfócitos foram fatores de risco independentes para COVID-19. A AUC da determinação combinada de NLR e CRP foi de 0,863, que foi maior do que a de NLR, PCR, WBC e porcentagem de linfócitos (AUC: 0,835, 0,775, 0,416 
Research, Society and Development, v. 10, n. 16, e164101623482, 2021

(CC BY 4.0) | ISSN 2525-3409 | DOI: http://dx.doi.org/10.33448/rsd-v10i16.23482

e 0,749 , respectivamente). Portanto, resultados mostraram que o NLR e PCR foram fatores de risco independentes para COVID-19, e a detecção combinada de NLR e PCR mostrou melhor desempenho diagnóstico para COVID-19.

No estudo de Javanmard et al. (2020), objetivaram buscar um marcador prognóstico confiável de gravidade da doença COVID-19. Para isso, Foram incluídos no estudo 508 pacientes com COVID-19 (59\% do sexo masculino), entre os quais 9,7\% estavam em estado grave, com pressão parcial de oxigênio (pO 2) <93\% e recebendo ventilação mecânica. A média de idade dos pacientes graves $(67,7 \pm 15,1$ anos $)$ foi significativamente maior do que os pacientes não graves $(56,8 \pm 17,1$ anos $)(P$ $<0,0001)$. Aproximadamente 39\% dos pacientes tinham pelo menos uma doença ou distúrbio subjacente. Doença vascular coronariana e diabetes mellitus foram mais comuns em pacientes graves, embora não tenham sido significativamente diferentes dos casos leves $(\mathrm{P}>0,05)$. A taxa de mortalidade em pacientes graves foi significativamente maior do que nos outros casos (60\% vs. 4,1\%; P <0,0001). A contagem média de leucócitos (leucócitos) em pacientes graves (9205 células / mm 3 ) foi significativamente maior do que em casos não graves (5963 células / mm 3 ) ( $\mathrm{P}<0,0001)$. A contagem de leucócitos foi> 10.000 células / mm 3 em 29,5\% dos casos graves e 8,6\% dos casos não graves ( $\mathrm{P}<0,0001$ ), enquanto a taxa de contagem de leucócitos < 4.000 células / mm 3 entre os pacientes moderados foi de $23 \%$ em contraste a zero em pacientes graves. A contagem média de linfócitos não diferiu entre pacientes graves (1409 células / mm 3 ) e pacientes não graves $(\mathrm{P}=0,4093)$. Em 7,3\% dos pacientes graves, a contagem de linfócitos era> 4000 células / mm 3em comparação com 1,1\% em pacientes não graves $(\mathrm{P}=0,003)$. A porcentagem de contagens de linfócitos $<1000$ células $/ \mathrm{mm} 3$ não foi diferente entre os dois grupos $(\mathrm{P}=$ 0,286). Em 26,8\% dos pacientes graves, a contagem de neutrófilos foi> 8.000 / mm 3 em comparação com $8,4 \%$ em pacientes não graves $(\mathrm{P}=0,003)$. No entanto, a porcentagem da contagem de neutrófilos <2500 / mm 3 em pacientes não graves foi de $21,4 \%$ em contraste com zero em pacientes graves. A porcentagem de NLR> 6,5 diferiu significativamente entre os dois grupos (56,1\% em pacientes graves vs. 20,0\% em pacientes não graves; $\mathrm{P}<0,0001)$, no entanto, os pacientes com NLR no intervalo 3,5-6,5 não diferiram $(\mathrm{P}=0,362)$. A proteína $\mathrm{C}$ reativa foi $\geq 10 \mathrm{mg} / \mathrm{L}$ em $84,9 \%$ de todos os pacientes, sem diferença significativa entre os grupos $(\mathrm{P}=0,552)$. A probabilidade de $\mathrm{NLR}>6,5$ associada à gravidade da doença em pacientes com idade $\geq 70$ anos foi quase o dobro da de outros, enquanto o sexo do paciente não teve efeito significativo. A chance de NLR> 6,5 associada à morte foi 1,44 [intervalo de confiança de 95\% (IC) 1,82-2,07] (P<0,0001). Em relação ao ajuste para idade e sexo, a chance de gravidade da doença em pacientes com contagem de leucócitos> 10.000 células / mm 3 e contagem de linfócitos $>4.000$ células / mm 3foram 4 e 6 vezes mais do que outros pacientes, respectivamente. NLR> 6,5 aumentou as chances de gravidade em 5 vezes e as chances de morte foram 1,76 (IC de 95\% 1,02-2,46) após o ajuste para idade e sexo (P <0,0001) (tabela 1 ). Em conclusão, o presente estudo apóia que a NLR pode ser um teste de ponto de atendimento rápido, fácil e, portanto, preferido para estratificação de pacientes e uma ferramenta eficiente para priorização de recursos do sistema de saúde.

No estudo de Belice at al. (2020), objetivaram comparar as razões neutrófilos-linfócitos de homens e mulheres com diagnóstico de COVID-19. Para isso, foi realizado um estudo com 80 pacientes e os dados foram obtidos retrospectivamente nos documentos eletrônicos do hospital. A razão neutrófilos-linfócitos foi estatisticamente significativa e maior no sexo masculino do que nas mulheres para todas as idades e pacientes geriátricos $(\mathrm{p}<0,05)$. Portanto, a maior proporção de neutrófilos-linfócitos em homens mais velhos com diagnóstico de COVID-19 pode ser uma razão para as taxas de mortalidade mais altas em homens. Esperamos que essas descobertas sejam úteis para estudos futuros.

No estudo de Sànchez et al. (2020) tiveram como objetivo estabelecer o melhor ponto de corte de NLR e LCR para predizer mortalidade em pacientes hospitalizados por COVID-19 no México. Para isso foi realizado um estudo transversal analítico de pacientes internados por COVID-19 grave em um hospital especializado. Dos 242 pacientes analisados, 34\% morreram. Os falecidos eram mais velhos (62 vs. 51 anos; $p<0,001)$, tinham maior prevalência de> 10 anos com hipertensão 
arterial sistêmica $(59,4$ vs. 45,1\%, p =0,022), bem como maior NLR (17,66 vs. . 8,31, p <0,001) e menor LCR (0,03 vs. 0,06, $\mathrm{p}<0,002)$ em relação aos que sobreviveram. Os pontos de corte para predizer mortalidade foram NLR $>12$ e LCR <0,03. A combinação de NLR / LCR teve sensibilidade de $80 \%$, especificidade de $74 \%$, valor preditivo positivo de 46,15\%, valor preditivo negativo de 93,02\% e odds ratio de 11,429 para prever mortalidade. Portanto NLR> 12 e LCR <0,03 são biomarcadores úteis para avaliar o risco de mortalidade em pacientes mexicanos com COVID-19 grave.

No estudo de Seyit et al. (2021) teve como objetivo investigar e comparar os impactos prognósticos de biomarcadores de CRP, contagem de leucócitos, NLR, PLR, largura de distribuição de células vermelhas (RDW) em casos COVID-19 confirmados em laboratório, bem como explorar os biomarcadores diagnósticos mais úteis e valores de corte ideais em pacientes COVID-19. Para esse fim, um total de 233 pacientes foram admitidos no Departamento de Emergência (ED) do Hospital Universitário de Pamukkale durante dois meses (março-abril de 2020) e foram submetidos a Sars CoV-2 PCR (Reação em Cadeia da Polimerase), hemograma completo (CBC) e PCR testes em sequência devido a reclamações do COVID19. Os resultados laboratoriais e os achados demográficos foram coletados do sistema de gestão de saúde pública retrospectivamente. Os pacientes com teste de PCR Sars CoV-2 positivo juntamente com dados de internação também foram registrados. A PCR (p = 0,0001), lactato desidrogenase $(\mathrm{LDH})(\mathrm{p}=0,038)$, PLR $(\mathrm{p}=0,0001)$ e NLR $(\mathrm{p}=0,001)$ permaneceram significativamente maiores nos pacientes com teste de PCR positivo para Sars CoV-2. Em contraste, os níveis de eosinófilos $(\mathrm{p}=0,0001)$, linfócitos $(\mathrm{p}=0,0001)$ e plaquetas $(\mathrm{p}=0,0001)$ foram calculados como significativamente mais elevados em pacientes Sars CoV-2 negativos. Logo, os níveis de PCR, LDH, PLR e NLR permaneceram significativamente mais elevados nos pacientes positivos para COVID-19, enquanto os níveis de eosinófilos, linfócitos e plaquetas estavam significativamente elevados nos pacientes negativos para COVID-19.

\section{Considerações Finais}

Constatou-se que houve associação entre o valor quantitativo das relações celulares com a evolução do paciente com COVID-19. Observou-se que quanto maior for a proporção de neutrófilos para linfócitos (NLR), a proporção de plaquetas para linfócitos (PLR), proporção de linfócitos para monócitos (LMR), pior será o prognóstico do paciente infectado pelo SARSCoV-2. Mais pesquisas são necessárias para confirmar nossos achados e para comparar a capacidade preditiva da NLR, PRL e LMR na evolução da infecção COVID-19.

\section{Referências}

Borger, B. et al. Systematic review with meta-analysis of the accuracy of diagnostic tests for COVID-19. American journal of infection control, 2020.

Fang, X. et al. Epidemiological, comorbidity factors with severity and prognosis of COVID-19: a systematic review and meta-analysis. Aging (Albany NY), v. 12, n. 13 , p. $12493,2020$.

Fu, J., Kong, J., Wang, W., Wu, M., Yao, L., Wang, Z., Jin, J., Wu, D., Yu, X. The clinical implication of dynamic neutrophil to lymphocyte ratio and D-dimer in COVID-19: A retrospective study in Suzhou China. Thromb Res. 2020 Aug;192:3-8. doi: 10.1016/j.thromres.2020.05.006. Epub 2020 May 6. PMID: 32407937; PMCID: PMC7201241.

Lauer, S. A. et al. The incubation period of coronavirus disease 2019 (COVID-19) from publicly reported confirmed cases: estimation and application. Annals of internal medicine, v. 172, n. 9 , p. 577-582, 2020

Gallo, M., B. et al. Predictors of COVID-19 severity: A literature review. Reviews in medical virology, v. 31, n. 1, p. 1-10, 2021.

Ponti, G., Maccaferri, M., Ruini, C., Tomasi, A., Ozben, T. Biomarkers associated with COVID-19 disease progression. Crit Rev Clin Lab Sci. 2020 Sep;57(6):389-399. doi: 10.1080/10408363.2020.1770685. Epub 2020 Jun 5. PMID: 32503382; PMCID: PMC7284147.

Liu, Y., Du, X., Chen, J., Jin, Y., Peng, L., Wang, H., Luo, M., Chen, L., \& Zhao, Y. (2020). Neutrophil-to-lymphocyte ratio as an independent risk factor for mortality in hospitalized patients with COVID-19. The Journal of infection, 81(1), e6-e12. https://doi.org/10.1016/j.jinf.2020.04.002 
Research, Society and Development, v. 10, n. 16, e164101623482, 2021 (CC BY 4.0) | ISSN 2525-3409 | DOI: http://dx.doi.org/10.33448/rsd-v10i16.23482

Fu, J., Kong, J., Wang, W., Wu, M., Yao, L., Wang, Z., Jin, J., Wu, D., \& Yu, X. (2020). The clinical implication of dynamic neutrophil to lymphocyte ratio and D-dimer in COVID-19: A retrospective study in Suzhou China. Thrombosis research, 192, 3-8. https://doi.org/10.1016/j.thromres.2020.05.006

Tatum, D., Taghavi, S., Houghton, A., Stover, J., Toraih, E., \& Duchesne, J. (2020). Neutrophil-to-Lymphocyte Ratio and Outcomes in Louisiana COVID-19 Patients. Shock (Augusta, Ga.), 54(5), 652-658. https://doi.org/10.1097/SHK.0000000000001585

Basbus, L., Lapidus, M. I., Martingano, I., Puga, M. C., \& Pollán, J. (2020). índice neutrófilo-linfocito como factor pronóstico de COVID-19 [Neutrophil to lymphocyte ratio as a prognostic marker in COVID-19]. Medicina, 80 Suppl 3, 31-36.

Ye, W., Chen, G., Li, X., Lan, X., Ji, C., Hou, M., Zhang, D., Zeng, G., Wang, Y., Xu, C., Lu, W., Cui, R., Cai, Y., Huang, H., \& Yang, L. (2020). Dynamic changes of D-dimer and neutrophil-lymphocyte count ratio as prognostic biomarkers in COVID-19. Respiratory research, 21 (1), 169. https://doi.org/10.1186/s12931-020-01428-7

Ma, A., Cheng, J., Yang, J., Dong, M., Liao, X., \& Kang, Y. (2020). Neutrophil-to-lymphocyte ratio as a predictive biomarker for moderate-severe ARDS in severe COVID-19 patients. Critical care (London, England), 24(1), 288. https://doi.org/10.1186/s13054-020-03007-0

Yang, A. P., Liu, J. P., Tao, W. Q., \& Li, H. M. (2020). The diagnostic and predictive role of NLR, d-NLR and PLR in COVID-19 patients. International immunopharmacology, 84, 106504. https://doi.org/10.1016/j.intimp.2020.106504

Chan, A. S., \& Rout, A. (2020). Use of Neutrophil-to-Lymphocyte and Platelet-to-Lymphocyte Ratios in COVID-19. Journal of clinical medicine research, 12(7), 448-453. https://doi.org/10.14740/jocmr4240

Ciccullo, A., Borghetti, A., Zileri Dal Verme, L., Tosoni, A., Lombardi, F., Garcovich, M., Biscetti, F., Montalto, M., Cauda, R., Di Giambenedetto, S., \& Gemelli against COVID Group (2020). Neutrophil-to-lymphocyte ratio and clinical outcome in COVID-19: a report from the Italian front line. International journal of antimicrobial agents, 56(2), 106017. https://doi.org/10.1016/j.ijantimicag.2020.106017

Wang, H., Zhang, Y., Mo, P., Liu, J., Wang, H., Wang, F., \& Zhao, Q. (2020). Neutrophil to CD4+ lymphocyte ratio as a potential biomarker in predicting virus negative conversion time in COVID-19. International immunopharmacology, 85, 106683. https://doi.org/10.1016/j.intimp.2020.106683

Seyit, M., Avci, E., Nar, R., Senol, H., Yilmaz, A., Ozen, M., Oskay, A., \& Aybek, H. (2021). Neutrophil to lymphocyte ratio, lymphocyte to monocyte ratio and platelet to lymphocyte ratio to predict the severity of COVID-19. The American journal of emergency medicine, 40, 110-114. https://doi.org/10.1016/j.ajem.2020.11.058

Liu, J., Liu, Y., Xiang, P., Pu, L., Xiong, H., Li, C., Zhang, M., Tan, J., Xu, Y., Song, R., Song, M., Wang, L., Zhang, W., Han, B., Yang, L., Wang, X., Zhou, G., Zhang, T., Li, B., Wang, Y., ... Wang, X. (2020). Neutrophil-to-lymphocyte ratio predicts critical illness patients with 2019 coronavirus disease in the early stage. Journal of translational medicine, 18(1), 206. https://doi.org/10.1186/s12967-020-02374-0

Jimeno, S., Ventura, P. S., Castellano, J. M., García-Adasme, S. I., Miranda, M., Touza, P., Lllana, I., \& López-Escobar, A. (2021). Prognostic implications of neutrophil-lymphocyte ratio in COVID-19. European journal of clinical investigation, 51(1), e13404. https://doi.org/10.1111/eci.13404

Kong, M., Zhang, H., Cao, X., Mao, X., \& Lu, Z. (2020). Higher level of neutrophil-to-lymphocyte is associated with severe COVID-19. Epidemiology and infection, 148, e139. https://doi.org/10.1017/S0950268820001557

Lian, J., Jin, C., Hao, S., Zhang, X., Yang, M., Jin, X., Lu, Y., Hu, J., Zhang, S., Zheng, L., Jia, H., Cai, H., Zhang, Y., Yu, G., Wang, X., Gu, J., Ye, C., Yu, X., Gao, J., Yang, Y., ... Sheng, J. (2020). High neutrophil-to-lymphocyte ratio associated with progression to critical illness in older patients with COVID-19: a multicenter retrospective study. Aging, 12(14), 13849-13859. https://doi.org/10.18632/aging.103582

Cai, J., Li, H., Zhang, C., Chen, Z., Liu, H., Lei, F., Qin, J. J., Liu, Y. M., Zhou, F., Song, X., Zhou, J., Zhao, Y. C., Wu, B., He, M., Yang, H., Zhu, L., Zhang, P., Ji, Y. X., Zhao, G. N., Lu, Z., ... Li, H. (2021). The Neutrophil-to-Lymphocyte Ratio Determines Clinical Efficacy of Corticosteroid Therapy in Patients with COVID-19. Cell metabolism, 33(2), 258-269.e3. https://doi.org/10.1016/j.cmet.2021.01.002

Bedel, C., \& Korkut, M. (2020). Neutrophil-To-Lymphocyte Ratio And Covid-19. Shock (Augusta, Ga.), Publish Ahead of Print, 10.1097/SHK.0000000000001712. Advance online publication. https://doi.org/10.1097/SHK.0000000000001712

Rizo-Téllez, S. A., Méndez-García, L. A., Flores-Rebollo, C., Alba-Flores, F., Alcántara-Suárez, R., Manjarrez-Reyna, A. N., Baltazar-López, N., HernándezGuzmán, V. A., León-Pedroza, J. I., Zapata-Arenas, R., González-Chávez, A., Hernández-Ruíz, J., Carrillo-Ruíz, J. D., Serrano-Loyola, R., GuerreroAvendaño, G., \& Escobedo, G. (2020). The Neutrophil-to-Monocyte Ratio and Lymphocyte-to-Neutrophil Ratio at Admission Predict In-Hospital Mortality in Mexican Patients with Severe SARS-CoV-2 Infection (Covid-19). Microorganisms, 8(10), 1560. https://doi.org/10.3390/microorganisms8101560

Yan, X., Li, F., Wang, X., Yan, J., Zhu, F., Tang, S., Deng, Y., Wang, H., Chen, R., Yu, Z., Li, Y., Shang, J., Zeng, L., Zhao, J., Guan, C., Liu, Q., Chen, H., Gong, W., Huang, X., Zhang, Y. J., Li, D. (2020). Neutrophil to lymphocyte ratio as prognostic and predictive factor in patients with coronavirus disease 2019: A retrospective cross-sectional study. Journal of medical virology, 92(11), 2573-2581. https://doi.org/10.1002/jmv.26061

Xu, J. B., Xu, C., Zhang, R. B., Wu, M., Pan, C. K., Li, X. J., Wang, Q., Zeng, F. F., \& Zhu, S. (2020). Associations of procalcitonin, C-reaction protein and neutrophil-to-lymphocyte ratio with mortality in hospitalized COVID-19 patients in China. Scientific reports, 10(1), 15058. https://doi.org/10.1038/s41598020-72164-7

Zhang, B., Zhou, X., Zhu, C., Song, Y., Feng, F., Qiu, Y., Feng, J., Jia, Q., Song, Q., Zhu, B., \& Wang, J. (2020). Immune Phenotyping Based on the Neutrophil-to-Lymphocyte Ratio and IgG Level Predicts Disease Severity and Outcome for Patients With COVID-19. Frontiers in molecular biosciences, 7 , 157. https://doi.org/10.3389/fmolb.2020.00157

Nalbant, A., Kaya, T., Varim, C., Yaylaci, S., Tamer, A., \& Cinemre, H. (2020). Can the neutrophil/lymphocyte ratio (NLR) have a role in the diagnosis of coronavirus 2019 disease (COVID-19)?. Revista da Associacao Medica Brasileira (1992), 66(6), 746-751. https://doi.org/10.1590/1806-9282.66.6.746 
Research, Society and Development, v. 10, n. 16, e164101623482, 2021

(CC BY 4.0) | ISSN 2525-3409 | DOI: http://dx.doi.org/10.33448/rsd-v10i16.23482

Wang, X., Li, X., Shang, Y., Wang, J., Zhang, X., Su, D., Zhao, S., Wang, Q., Liu, L., Li, Y., \& Chen, H. (2020). Ratios of neutrophil-to-lymphocyte and platelet-to-lymphocyte predict all-cause mortality in inpatients with coronavirus disease 2019 (COVID-19): a retrospective cohort study in a single medical centre. Epidemiology and infection, 148, e211. https://doi.org/10.1017/S0950268820002071

Liu, Y. P., Li, G. M., He, J., Liu, Y., Li, M., Zhang, R., Li, Y. L., Wu, Y. Z., \& Diao, B. (2020). Combined use of the neutrophil-to-lymphocyte ratio and CRP to predict 7-day disease severity in 84 hospitalized patients with COVID-19 pneumonia: a retrospective cohort study. Annals of translational medicine, $8(10)$, 635. https://doi.org/10.21037/atm-20-2372

Qun, S., Wang, Y., Chen, J., Huang, X., Guo, H., Lu, Z., Wang, J., Zheng, C., Ma, Y., Zhu, Y., Xia, D., Wang, Y., He, H., Wang, Y., Fei, M., Yin, Y., Zheng, M., Xu, Y., Ge, W., Hu, F., ... Zhou, J. (2020). Neutrophil-to-Lymphocyte Ratios Are Closely Associated With the Severity and Course of Non-mild COVID19. Frontiers in immunology, 11, 2160. https://doi.org/10.3389/fimmu.2020.02160

Liu, L., Zheng, Y., Cai, L., Wu, W., Tang, S., Ding, Y., Liu, W., Kou, G., Xiong, Z., Wang, S., \& Zheng, S. (2021). Neutrophil-to-lymphocyte ratio, a critical predictor for assessment of disease severity in patients with COVID-19. International journal of laboratory hematology, 43(2), 329-335. https://doi.org/10.1111/ijlh.13374

Pimentel, G. D., Dela Vega, M., \& Laviano, A. (2020). High neutrophil to lymphocyte ratio as a prognostic marker in COVID-19 patients. Clinical nutrition ESPEN, 40, 101-102. https://doi.org/10.1016/j.clnesp.2020.08.004

Eslamijouybari, M., Heydari, K., Maleki, I., Moosazadeh, M., Hedayatizadeh-Omran, A., Vahedi, L., Ghasemian, R., Sharifpour, A., \& Alizadeh-Navaei, R. (2020). Neutrophil-to-Lymphocyte and Platelet-to-Lymphocyte Ratios in COVID-19 Patients and Control Group and Relationship with Disease Prognosis. Caspian journal of internal medicine, 11(Suppl 1), 531-535. https://doi.org/10.22088/cjim.11.0.531

Mousavi-Nasab, S. D., Mardani, R., Nasr Azadani, H., Zali, F., Ahmadi Vasmehjani, A., Sabeti, S., Alavi Darazam, I., \& Ahmadi, N. (2020). Neutrophil to lymphocyte ratio and C-reactive protein level as prognostic markers in mild versus severe COVID-19 patients. Gastroenterology and hepatology from bed to bench, 13(4), 361-366.

Vafadar Moradi, E., Teimouri, A., Rezaee, R., Morovatdar, N., Foroughian, M., Layegh, P., Rezvani Kakhki, B., Ahmadi Koupaei, S. R., \& Ghorani, V. (2021). Increased age, neutrophil-to-lymphocyte ratio (NLR) and white blood cells count are associated with higher COVID-19 mortality. The American journal of emergency medicine, 40, 11-14. https://doi.org/10.1016/j.ajem.2020.12.003

Carpio-Orantes, L. D., García-Méndez, S., \& Hernández-Hernández, S. N. (2020). Neutrophil-to-lymphocyte ratio, platelet-to-lymphocyte ratio and systemic immune-inflammation index in patients with COVID-19-associated pneumonia. Índices neutrófilo/linfocito, plaqueta/linfocito e inmunidad/inflamación sistémica en pacientes con neumonía por COVID-19. Gaceta medica de Mexico, 156(6), 527-531. https://doi.org/10.24875/GMM.M21000480

Yufei, Y., Mingli, L., Xuejiao, L., Xuemei, D., Yiming, J., Qin, Q., Hui, S., \& Jie, G. (2020). Utility of the neutrophil-to-lymphocyte ratio and C-reactive protein level for coronavirus disease 2019 (COVID-19). Scandinavian journal of clinical and laboratory investigation, 80(7), 536-540. https://doi.org/10.1080/00365513.2020.1803587

Haghjooy Javanmard, S., Vaseghi, G., Manteghinejad, A., \& Nasirian, M. (2020). Neutrophil-to-Lymphocyte ratio as a potential biomarker for disease severity in COVID-19 patients. Journal of global antimicrobial resistance, 22, 862-863. https://doi.org/10.1016/j.jgar.2020.07.029

Belice, T., Demir, I., \& Yüksel, A. (2020). Role of neutrophil-lymphocyte-ratio in the mortality of males diagnosed with COVID-19. Iranian journal of microbiology, 12(3), 194-197.

Albarrán-Sánchez, A., González-Ríos, R. D., Alberti-Minutti, P., Noyola-García, M. E., Contreras-García, C. E., Anda-Garay, J. C., Martínez-Ascencio, L. E., Castillo-López, D. J., Reyes-Naranjo, L. A., Guízar-García, L. A., Flores-Padilla, G., \& Ramírez-Rentería, C. (2020). Association of neutrophil-to-lymphocyte and lymphocyte-to-C-reactive protein ratios with COVID-19-related mortality. Asociación de los índices neutrófilo/linfocito y linfocito/proteína C reactiva con mortalidad por COVID-19. Gaceta medica de Mexico, 156(6), 553-558. https://doi.org/10.24875/GMM.M21000481

Seyit, M., Avci, E., Nar, R., Senol, H., Yilmaz, A., Ozen, M., Oskay, A., \& Aybek, H. (2021). Neutrophil to lymphocyte ratio, lymphocyte to monocyte ratio and platelet to lymphocyte ratio to predict the severity of COVID-19. The American journal of emergency medicine, 40, 110-114. https://doi.org/10.1016/j.ajem.2020.11.058 